\title{
Aristotle's Theology and its Relation to the Science of Being qua Being
}

\author{
Shane Duarte
}

\section{Introduction}

The aim of this paper is to develop and defend an answer to a longstanding interpretive problem confronted by scholars of Aristotle viz., how to reconcile the two, apparently competing conceptions of metaphysics to be found in his work on first philosophy.

In Metaphysics IV 1 Aristotle declares that metaphysics studies being $q u a$ being and the attributes which belong to beings precisely insofar as

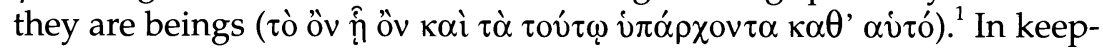
ing with his view that scientific understanding of an object requires an understanding of its principles and causes, ${ }^{2}$ here Aristotle also characterizes metaphysics as involving a search after the principles and causes of beings precisely insofar as they are beings. ${ }^{3}$ Moreover, in Metaphysics VI 1 Aristotle further claims that, in its concern to identify the principles and causes of that which is qua thing that is, metaphysics is to

1 Metaph IV 1, 1003a21-2

2 See $A P o$ II 8, 93a3-4 and $P h$ I 1, 184a10-14.

3 Metaph IV 1, 1003a31-2; see also Metaph VI 1, 1025b3-4. On the view to be argued for here, the claim that metaphysics deals with the principles and causes of beings $q u a$ beings is also foreshadowed in Metaph I 1-2 by Aristotle's description of wisdom ( = first philosophy) as having to do with the highest causes and principles. 
be contrasted with the special sciences (e.g., physics), which deal with some proper subset of existent things and their causes. ${ }^{4}$ That is to say, the physicist, for example, will aim to determine the principles, causes and attributes that attach to natural substances insofar as they are natural substances. The metaphysician, by contrast, will seek to determine the principles, causes and attributes of all beings - including natural substances - insofar as they are beings.

In Metaphysics VI 1 Aristotle seems also to suggest that metaphysics, conceived as determining the principles and causes of that which is $q u a$ thing that is, serves a foundational role with respect to the sciences which, like physics or mathematics, deal with particular genera of being. ${ }^{5}$ Specifically, Aristotle observes that none of the special sciences demonstrates the essence of its subject-genus, but instead posits what the essence is and then goes on to demonstrate the essential attributes that belong to the genus. Aristotle also observes that neither does any of the special sciences show that its subject-genus exists, since 'it belongs to the same line of thought to show what it is ( $\left.\tau^{\prime} \dot{\varepsilon} \sigma \tau \imath\right)$ and that it is ( $\varepsilon \dot{i}$

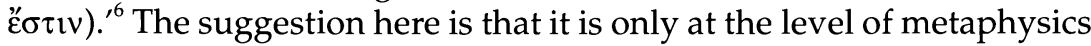
that these assumptions regarding the essence and existence of a special science's subject-genus are confirmed by means of some kind of demonstration or proof. ${ }^{7}$

On the basis of the texts mentioned thus far, then, it would seem that, according to Aristotle, metaphysics (i) studies beings merely insofar as they are beings (i.e., inquires into the principles and causes of that which is qua thing that is), (ii) somehow thereby establishes the existence and the essence of the particular genera that are the concern of the several special sciences, and (iii) determines, presumably by means

4 Metaph VI 1, 1025b4-10

5 Metaph VI 1, 1025b10-18

6 Metaph VI 1, 1025b17-18

7 This interpretation of the passage, according to which metaphysics somehow proves the principles of the special sciences, has been challenged by Gómez-Lobo (1978). Motivating his rejection of the traditional interpretation, I think, is the fact that it is difficult to see how, or in what sense, metaphysics might supply or confirm the principles of the special sciences. This is an issue I plan to discuss in a future paper. 
of demonstrations, ${ }^{8}$ the attributes that attach to beings merely insofar as they are beings. ${ }^{9}$

Later in Metaphysics VI 1, however, Aristotle offers a further characterization of metaphysics that seems prima facie inconsistent with the foregoing characterization of it as the science of being qua being. Indeed, Aristotle seems to identify this science with theology, which, rather than dealing with being in general, clearly deals with a particular kind of being (i.e., the divine). Specifically, Aristotle appeals to the criteria of separateness and immobility to classify items as objects of physics or mathematics, notes that there may be something (i.e., the separate and immobile, later identified with the divine) which falls outside the scopes of these two sciences, and states that, if such a thing exists, it will be studied by metaphysics. ${ }^{10}$

Now, one might think that in assigning the study of the separate and immobile (i.e., the divine, a particular kind of being) to metaphysics, Aristotle is simply concerned to point out that separate and immobile beings fall under the scope of metaphysics merely by virtue of this science's maximally wide domain, which is being as such. But not only does Aristotle seem at one point to identify metaphysics with theology, ${ }^{11}$ he himself also recognizes that there might seem to be some tension between his characterization of metaphysics as concerned with separate and immobile beings and his further characterization of it as concerned with beings as such. For he says:

One might indeed raise the question whether first philosophy is universal, or deals with one genus, i.e., some one kind of being; for not even the mathematical sciences are all alike in this respect - geometry and astronomy deal with a certain particular kind of thing, while universal mathematics applies alike to all. We answer that if there is no substance other than those which are formed by nature, natural in the Aristotelian sense of 'science,' holding instead that Aristotle's procedure in this work is dialectical - e.g., Leszl (1975) and Irwin (1988). For reasons that will become clear during the course of this paper, I think this interpretation is mistaken.

10 Metaph VI 1, 1025b18-6a16

11 Metaph VI 1, 1026a18-21 
science will be the first science; but if there is an immovable substance, the science of this must be prior and must be first philosophy, and universal in this way, because it is first. And it will belong to this to consider being qua being - both what it is and the attributes which belong to it qua being. (Metaph VI 1, 1026a23-33, trans. in Barnes [1984])

Aristotle, then, seems clearly to think that it falls to metaphysics to study the separate and immobile as such.

The most pressing question that arises here is this: How does Aristotle take theology to be related to metaphysics? Does he take metaphysics to be exclusively concerned with the divine, and this in such a way that it makes no attempt whatsoever to relate knowledge of the divine to a knowledge of other beings (sc. insofar as they are beings)? The Latin Commentators of Aristotle recognized the possibility of understanding Aristotle's metaphysics purely as a theology when they posed the question of whether God or being is the object of metaphysics. However, the majority of them denied that God is, according to the Philosopher, the object of metaphysics, seeing in Aristotle's claim that the science of separate substance is 'universal because first' an explanation of why theology is a central part of the science of being qua being (notwithstanding theology's special focus on separate and immobile entities). ${ }^{12}$ According to these commentators, necessary for an understanding of how theology could constitute a part of the universal science of being is Aristotle's view that the unmoved movers are causes of, and thus explanatorily prior to, all other beings (in the first instance, explanatorily prior to all other substances, but in the second instance, explanatorily prior to all non-substantial beings as well, since substances are themselves explanatorily prior to non-substantial beings). ${ }^{13}$ Thus, since (i) the study of being qua being involves an inquiry into the principles and causes that attach to beings merely insofar as they are beings, and (ii)

12 See, e.g., John Duns Scotus, Reportatio IA, prol, q 3, a 1, where he sides with Avicenna against Averroes in concluding that being (rather than God) is, according to Aristotle, the subject of metaphysics. The same view is articulated by Albertus Magnus in his commentary on Aristotle's Metaphysics, lib 1, tract 1, cap 2. For Thomas Aquinas' view, see below.

13 See Albertus Magnus' commentary on Aristotle's Metaphysics, lib 4, tract 1, cap 3, Thomas Aquinas, In Duodecim Libros Metaphysicorum Aristotelis Expositio, lib 4, lec 1, and John Duns Scotus, Expositio In Duodecim Libros Metaphysicorum Aristotelis, lib 4, summa prima, cap 1 . 
the unmoved movers are principles and causes of every being (both of themselves and of all other beings ${ }^{14}$ ), and therefore principles and causes of beings precisely insofar as they are beings, ${ }^{15}$ theology forms a part of the science of beings qua beings. For this reason, in the prologue to his commentary on Aristotle's Metaphysics, Thomas Aquinas denies that God is the object of metaphysics, observing that

although this science studies the three things mentioned earlier [viz., first causes, maximally universal principles and separate substances], still, it does not study any of them as its subject, but only being in general. For the subject of a science is the thing whose causes and attributes we seek, and not the very causes of the genus under investigation. For cognition of the causes of some genus is the end which investigation in a science attains. ${ }^{16}$

As the passage shows, according to Thomas, Aristotle does not straightforwardly identify metaphysics with theology, but rather takes theology to be one part of metaphysics - a part dealing with principles and causes of that which is qua thing that is.

Now this interpretation of Aristotle's Metaphysics (in its essentials, at least) has found its champions in the last century. ${ }^{17}$ But it has not gained widespread acceptance among modern scholars of Aristotle. Indeed, modern responses to the problem of Aristotle's ostensibly competing

14 At Metaph VI 1, 1026a17-18, Aristotle states that the divine separate substances are causes of the heavenly bodies, and at Cael I 9, 279a28-30, he says that beings in the sublunary world depend for their existence on the heavenly bodies. Further, at Metaph XII 7, 1072b13-14, Aristotle says that both the heavens and the world of nature depend on the divine separate substances.

15 The inference here from 'the unmoved movers are principles and causes of every being' to 'the unmoved movers are principles and causes of beings precisely insofar as they are beings' will be discussed below.

16 '... quamvis ista scientia praedicta tria consideret, non tamen considerat quodlibet eorum ut subiectum, sed ipsum solum ens commune. Hoc enim est subiectum in scientia, cuius causas et passiones quaerimus, non autem ipsae causae alicuius generis quaesiti. Nam cognitio causarum alicuius generis, est finis ad quem consideratio scientiae pertingit.' (Aquinas [1964, 2]).

17 Modern proponents of this interpretation include: Décarie (1961), Verbeke (1979) and Follon (1992). To this list one might also add Reale (1979), though Reale's interpretation of the expression ' $\tau$ ò ôv tional interpretation advocated by Décarie, Verbeke and Follon. 
characterizations of metaphysics (on the one hand, as theology, and on the other hand, as the science of beings as such) have been many and varied. Some interpreters, for example, have denied that the two, apparently competing, conceptions of metaphysics can be reconciled. ${ }^{18}$ Others have responded to the problem by denying that the study of $\tau$ ò ôv óv is in fact to be understood as an 'ontology', Aristotle's metaphysics being strictly a theology. ${ }^{19}$ And still others have claimed to find a way of

18 Natorp (1888) was motivated for this reason to take passages suggesting an identification of metaphysics with theology to be the work of Platonizing early Peripatetics. On the other hand, Jaeger (1948, Chs 7 and 8) saw the presence of these ostensibly inconsistent characterizations of metaphysics as a result of Aristotle's own philosophical development: the conception of metaphysics as theology is attributed to an early, Platonic stage of Aristotle's career, while the conception of metaphysics as a study of being in general (as an 'ontology') is attributed to a later, more properly 'Aristotelian' stage. And Elders (1962) agreed with Jaeger on the need for a developmental explanation of the two rival accounts, but argued, against Jaeger, that the conception of metaphysics as 'ontology' belonged to Aristotle's earlier, Platonic stage of development, the conception of metaphysics as theology being the more properly 'Aristotelian' conception. Another interpreter who sees an irreconcilable conflict between the two characterizations of metaphysics is Aubenque (1962).

19 Owens (1978), Merlan (1960) and Merlan (1968). Here it is important to note that, in denying that there is any ontology to be found in Aristotle's Metaphysics, both Owens and Merlan understand 'ontology' as Natorp did, as a study of ens commune - i.e., a study of the concept with the widest extension and least content. Now, these two authors take the expression 'being qua being' to refer exclusively (Merlan), or ultimately (Owens), to separate substance, the object of theology. On their view, then, although it can be granted that for Aristotle an understanding of the divine contributes to an understanding of other beings because it is somehow prior in the order of explanation to other beings, Aristotle's metaphysics is properly to be understood as a theology. Owens takes Aristotle to be of the view that the term 'substance' is pros hen equivocal (on which, see next note), the primary sense of 'substance' being that in which it is said of the unmoved movers. According to Owens, underlying this logical relation, in which consists the dependence of an understanding of material substance on an understanding of separate substance, is Aristotle's view that material substances strive to imitate the being of the unmoved movers. As Owens puts it, final causality 'accomplishes what participation or any other Platonic explanation was unable to do' (Owens [1978, 464]). According to Merlan, on the other hand, an understanding of separate substance contributes to an understanding of material substances because the primary kind of entity is present in other things as a kind of ingredient, as that which makes a thing a being (Merlan [1960, 169] and Merlan [1968, 190-2]). Another proponent of the view that Aristotle's metaphysics is properly understood simply as a theology is Hahn (1979). 


\author{
reconciling the two apparently competing conceptions of metaphysics \\ in Aristotle's doctrine of pros hen equivocation. ${ }^{20}$
}

20 Proponents of this interpretation include: Patzig (1979), Frede (1987), Ludwig (1989), and Fraser (2002). In Aristotle, pros hen equivocation is a kind of systematic ambiguity that attaches to terms. One of Aristotle's favourite examples of a pros hen equivocal term is 'healthy'. 'Healthy', as said of animals, is said in a sense different from that in which it is said of food, and both of these senses are different from the sense in which 'healthy' is said of animal excreta. 'Healthy' is said of food when it is conducive to health in the animal, while 'healthy' is said of the kind of excreta that is a sign of health in the animal. In other words, there is a so-called 'focal meaning' of the word with respect to which its other meanings must be defined. (In this example, the focal meaning of 'healthy' is the sense in which it is said of animals.) In the Metaphysics, Aristotle first discusses pros hen equivocation at Metaph IV 2, 1003a33-b16, in order to explain why the science of being in general counts as a science, notwithstanding (i) Aristotle's view, made clear in the Posterior Analytics, that a science must be the science of some single genus and (ii) his acknowledgement that being is not in fact a genus (APo II 7, 92b14). His answer is that 'being' is pros hen equivocal insofar as it is said of different kinds of being, and that, just as it falls to a single science to study all healthy things, notwithstanding the pros hen equivocal character of 'healthy,' it falls to a single science to study all beings. To this, Aristotle adds another observation - namely, that since science deals chiefly with that which is first, i.e., the thing on which the other items dealt with in the science depend, the metaphysician will be chiefly concerned with the principles and causes of substance (Metaph IV 2, 1003b16-19).

Now, according to those interpreters who take Aristotle's doctrine of pros hen equivocation to be the key to reconciling his ostensibly conflicting characterizations of metaphysics, not only does Aristotle think that 'being' is pros hen equivocal (with the result that non-substantial items, on his view, must be defined by reference to substance - or 'by addition' ( $\dot{\kappa} \kappa \pi \rho \circ \sigma \varepsilon \dot{\varepsilon} \sigma \varepsilon \omega \varsigma)$, as Aristotle puts it at Metaph VII 5, 1031a1-14); he also thinks that 'substance' is pros hen equivocal insofar as it is said of both composite and separate substances, with the result that, according to Aristotle, composite substances must be understood and defined by reference to separate substances (or to the mode of being enjoyed by separate substances). Thus, for these interpreters, theology forms a part of the science of being qua being because an understanding of separate substances is in this way necessary for an understanding of all other substances.

This interpretation, which I take to be the main competitor of the traditional interpretation advocated by Aquinas, is not without its problems. For an interesting critique of the view, see Berti (2001). Perhaps the most significant of these, however, is that it seems implicitly to rely on an erroneous assumption - namely, that for Aristotle an understanding of the divine could have a bearing on an understanding of beings generally only if an understanding of the unmoved movers is taken to be a necessary reference point for an understanding of other substances, and this in the same way that an understanding of substance constitutes a necessary reference point for an understanding of items in the non-substantial categories. This seems unwarranted, given Aristotle's view that the unmoved movers 
My purpose in this paper is to present and defend a version of the traditional interpretation articulated by Aquinas, according to which theology constitutes one part of metaphysics because it deals with beings that are prior in the order of scientific explanation to everything else that exists. Generally put, my claim is that when he states that theology is universal because first, Aristotle means that theology is universal in the sense that an understanding of the unmoved movers is involved in a complete scientific understanding of any being, either because that being is an unmoved mover or because it is causally dependent on the unmoved movers.

Of course, it has been duly noted by those favouring the interpretation for which I am arguing here that, according to Aristotle, to understand what something is involves an understanding of its causes, both proximate and remote. But most of the attention has focused on the Metaphysics itself. What I shall offer here instead is an investigation aimed at showing how Aristotle's conception of scientific understanding (according to which scientific understanding of an object involves an understanding of its causes) structures his manner of proceeding in his physical works. For I claim that once it is recognized how Aristotle's natural philosophical inquiries are structured in accordance with this conception, the theological aspect of the Metaphysics emerges as something quite intelligible and to be expected.

\section{Preliminaries: Two Senses of 'Universal Cause'}

In this section my goal is to develop some ideas that are crucial to the interpretation for which I am arguing. Although some of the points I shall be making here are widely recognized, or have been anticipated by other scholars, ${ }^{21}$ to the best of my knowledge, no one has systematically identified and developed these ideas in quite the way I will be doing so here.

It is well known that, according to Aristotle, when searching for the cause of some effect, one must take care to ensure that the two items al-

are causes of all other beings, and his insistence that scientific understanding of an object $x$ requires an understanding of $x^{\prime}$ s principles and causes - both proximate and remote.

21 See the first three works mentioned in note 17. See also Mansion (1956). 
leged to be causally related are, so to speak, commensurable. For example, Aristotle would deny the claim that matter, generally, is a material cause of horses without qualification, since, according to him, matter as such is rather a material cause of composite substances as such, while the material cause of horses, which together constitute a particular species of composite substance, is a particular kind of matter - i.e., 'horse stuff'. Note that in this example matter stands to horse stuff as composite substance stands to horse - i.e., as a genus stands to one of its species. In other words, according to Aristotle, commensurability of cause and effect can be ensured by correlating generic effects with generic causes, and specific effects with specific causes. ${ }^{22}$

It is a central claim of this paper, however, that for Aristotle the correlating of generic effects with generic causes, and the correlating of specific effects with specific causes, is not the only way to ensure commensurability of cause and effect - and this because a cause can, according to Aristotle, be universal in either of two senses: either (i) because it is itself a universal, or (ii) because it is first in some order and therefore a cause with respect to everything else in that order. Consider again, for example, the familiar Aristotelian claim that matter is a cause of natural substances. The import of this claim is simply that every species of composite substance, from the sublunary elements all the way through to humans and the heavenly bodies, has some kind of matter as an intrinsic principle of its being. ${ }^{23}$ Here, the term 'matter' is a generic term - i.e., a universal - that is equally applicable to the various kinds of matter that are peculiar to various lowest species (infimae species) of composite substance, and for this reason matter, as such, may be characterized as a 'universal cause' of composite substances. Now consider, on the other hand, the claim that prime matter, in particular, is a material cause of perishable substances generally. ${ }^{24}$ The import of this

22 See $P h$ II 3, esp. 195b25ff.

23 I take it that Aristotle believes in the existence of a matter common to the four sublunary elements, which constitutes, together with the primary qualities (hot/cold, dry/wet), these same elements. Challenges to this, the traditional view, can be found in Charlton (1970, Appendix) and in Gill (1989, Chap. 2 and Appendix).

24 I take it that Aristotle does not hold that the ether is a composite of prime matter and some quality or qualities. But even if Aristotle does take the ether to be a composite, the general point still stands: prime matter will in that case be a universal cause of all composite substances, rather than a universal cause of just those composite substances which are perishable. 
claim is that prime matter constitutes a more or less remote material substrate for all perishable substances. In this case, commensurability of cause and effect is not ensured by correlating a generic cause with a generic effect. Rather, the universality of prime matter as a material principle with respect to all perishable substances consists in its being first in the domain of sublunary materials - i.e., in its being a more or less proximate material principle of every other kind of sublunary matter. ${ }^{25}$ The suggestion, then, is that for Aristotle the more remote the matter one specifies as a material cause, the larger the domain with respect to which it serves as such a cause. From this it follows that for Aristotle the correlating of generic effects with generic causes, and the correlating of specific effects with specific causes, is not the only way to ensure commensurability of cause and effect: a cause may be more or less universal according as it is more or less remote in some order of causes.

That Aristotle countenances talk of prime matter's being a material principle of all perishable substances is implied by what he says in the following passage:

On the topic of material substance, we must notice that even if everything does come from the same primary stuff, or stuffs, and even if it is the same matter that functions as a principle of the things that come into being, nevertheless there is a different matter appropriate to each

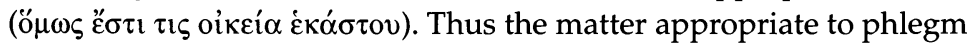
is sweet or fatty stuff, while that appropriate to bile is stuff which is bitter or something else; but these latter perhaps come from the same stuff. The same thing will come to have several matters when one is the matter of the next; thus phlegm may come from what is fat and from what is sweet, if fat itself comes from what is sweet. (Metaph VIII 4, 1044a15-22, trans. Bostock)

In recognition of the fact that one thing may have more than one matter when its proximate matter is itself a composite of matter and form, Aristotle observes in this passage that each lowest species of substance

25 'Our view is that there is a matter of the perceptible bodies, but that it is not separable but is always together with a contrariety, from which the so-called 'elements' come to be....so first that which is perceptible body in potentiality is principle, and secondly the contrarieties (I mean, for example, heat and cold), and only thirdly fire and water and the like' (GC II 1, 329a24-35, trans. Williams). 
has a matter that is appropriate (oikeí $\alpha$ ) or peculiar to it, by which he evidently means, in this context, its proximate matter. This is not to say that a lowest species of composite substance $x$ with proximate matter $y$ will necessarily be the only thing with $y$ as a material cause, for if $x$ itself serves as matter with respect to some other species of composite substance $z$, then $z$ too will in some way have $y$ as a material principle of its being. It is merely to say that $x$ and $z$ will have different proximate material causes. Now, although this claim might stand in need of qualification because Aristotle himself seems at one point to grant that specifically different substances can have the same proximate matter where the moving causes of their generation are specifically differ$\mathrm{ent}^{26}$ the implication of the passage quoted above is, nonetheless, that the more remote matter of a lowest species of composite substance can be a material principle that this lowest species has in common with some other lowest species of composite substance. For this very reason, shortly after this passage, Aristotle says that in the enumeration

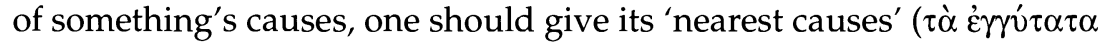
$\left.\alpha_{i}^{\prime \prime} i \alpha\right)$, and, in order to illustrate the point, he notes that it 'will not do to say that the matter is fire or earth; one must give the matter peculiar

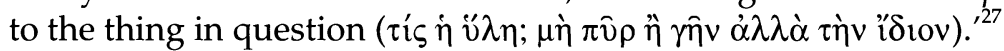

According to Aristotle, then, it makes sense to speak of prime matter as a material principle of all perishable substances. In other words, the correlating of generic effects with generic causes, and the correlating of specific effects with specific causes, is not, according to Aristotle, the only way to ensure commensurability of cause and effect.

The following passage from the de Anima can also be cited as evidence for this conclusion: 'the nutritive soul belongs also to the other living things and is the first and most commonly possessed potentiality of the

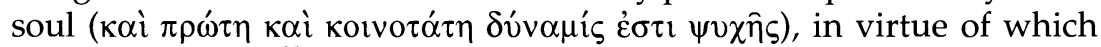
they all have life. ${ }^{28}$ If it were a matter here of correlating generic effects with generic causes, Aristotle would have said that the soul - rather than the nutritive soul - is that in virtue of which living things live.

26

27

\section{suffic} sufficiency, rather than mistakenness, of specifying the remote matter of a thing as
a material cause of it. 
Here, then, we have an instance of a cause that is conceived to be universal with respect to some domain (i.e., the domain of living things) by virtue of being first in some order of causes (i.e., first in the order of the powers of soul). Indeed, in this passage, the nutritive power of the soul is not only called the $\pi \rho \omega \dot{\tau \eta} \delta \dot{v} v \alpha \mu 1 \varsigma \psi v \chi \bar{\eta} \varsigma$ - i.e., the first power

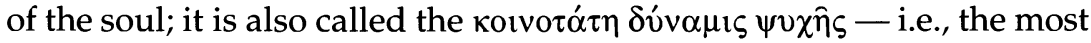
common power of the soul.

According to Aristotle, then, there are two senses in which a cause can be universal. In one sense, a cause (e.g., matter) can be universal because it is itself a universal under which various species of cause (e.g., the matter of a horse, the matter of a human being) are subsumed. ${ }^{29}$ In another sense, a cause can be universal with respect to some domain, not because it is itself a universal, but because of its position in some order of causes (e.g., prime matter, which is first in the order of sublunary materials and thus a more or less remote material cause of all perishable substances) - and this despite the fact that such a cause will invariably be a universal, at least if it qualifies as an explanation in the context of scientific inquiry. ${ }^{30}$

Now, recognition of the sense in which a cause, according to Aristotle, can be universal with respect to some domain by virtue of being first in some order of causes puts us in a position to make the following point: If Aristotle is prepared to countenance talk of prime matter's being a principle of all perishable substances, then it might seem fair to speak of prime matter's being a principle of (say) horses (a particular kind of perishable substance) - which would violate the requirement that one specify a cause commensurable with the effect in question. Now, it is, I argue, precisely in contexts such as these that the ' $q u a^{\prime}$ operator finds one of its uses in Aristotle: in order to acknowledge that prime matter is a material principle of horses, while yet marking the fact that the domain with respect to which prime matter serves as a cause is more extensive than the class of horses and includes all perishable substances, Aristotle will specify that it is qua perishable substances that horses have prime matter as a principle of their being. ${ }^{31}$

29 Of course, matter is a universal cause with respect, specifically, to the domain of composite substances.

30 See Metaph VII 15, 1039b20-40a7.

31 It is clear that for Aristotle the ' $q u a$ ' operator has such a function in the analogous case of correlating attributes with their proper subjects (i.e., their commensurately 
Similarly, he will specify that it is qua living things that animals have the nutritive soul as a principle of their existence.

This last point is crucial. What it reveals is that for Aristotle, when it comes to identifying those causes of a thing which are universal with respect to some domain by virtue of their position in some order of causes, the enumeration of all these causes and principles, both proximate and remote, is at the same time an enumeration of the principles and causes that attach to the thing insofar as it is a member of multiple natural kinds. For example, on this view, to inquire into the proximate causes of horses is simply to inquire into the causes of horses precisely insofar as they are horses (or: to inquire into the causes of a horse qua horse - or again: into the causes of horses as such). To inquire into the proximate causes of these proximate causes is to inquire into the causes of horses insofar as they are (not horses, but) members of some more general kind (i.e., the genus which has the lowest species horse as one of its species or immediate divisions). And to inquire into the proximate causes of these last proximate causes is to inquire into the causes of horses insofar as they are members of some even more general kind (i.e., the genus of which the last-mentioned genus is a species or immediate division). And so on.

On the basis of this last point, the thesis of this paper ${ }^{32}$ can now be clarified in the following way. Because theology deals with substances that (i) are prior in the order of explanation to every other kind of substance (since the unmoved movers are causes and principles of every other kind of substance) and (ii) are furthermore first in that same order (since an unmoved mover has no cause or principle distinct from itself, and can therefore be called causa sui), theology deals with the most remote of those causes which are universal with respect to some domain

universal subjects), which are likewise conceived to be causes in relation to their attributes. The following passage, from APo I 5, can be cited as evidence: 'it might be thought that proportion alternates for items as numbers and as lines and as sol-

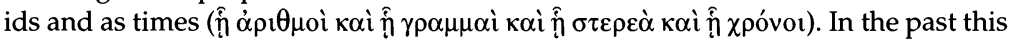
used to be proved separately, although it is possible to prove it of all cases by a single demonstration: because all these items - numbers, lengths, times, solids - do not constitute a single named item and differ in form from one another, they used to be taken separately. Now, however, it is proved universally: what they suppose to hold of them universally does not hold of them as lines or as numbers but as this

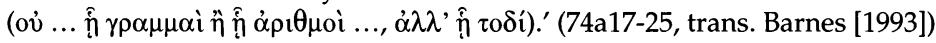

32 Viz., that theology forms one part of one division of the science of being, i.e., the division devoted to the principles and causes of that which is qua thing that is. 
by virtue of their positions in some order of causes. Accordingly, since the more remote the cause, the larger the domain with respect to which it serves as a cause, the domain with respect to which the objects of theology are causes will be the maximally wide domain - i.e., the domain of substance, or rather, the entire domain of being. (Since the unmoved movers are in the first instance causes of substance as such, and substances are in turn principles of all non-substantial items, the unmoved movers are also, in the second instance, causes and principles of being as such.) In other words, since scientific understanding of a substance involves an understanding of its causes insofar as it belongs to various natural kinds, and metaphysics investigates substances insofar as they belong to a most general kind or highest genus, metaphysics will involve an investigation into the most remote causes of substances among which are the unmoved movers, the objects of theology.

It should further be noted that an important question naturally arises in the light of the distinction between (i) causes that are universal with respect to some domain by virtue of the fact that they are themselves universals and (ii) causes that are universal with respect to some domain, not because they are universals, but because of their position in some order of causes. The question is this: How, according to Aristotle, are explanatory accounts which are cast in terms of causes that are universal in the former sense related to explanatory accounts which are cast in terms of causes that are universal in the latter sense? The evidence suggests that for Aristotle the former (i.e., explanatory accounts cast in terms of causes that are universal by virtue of the fact that they are themselves universals) serve as means towards the formulation of the latter (i.e., explanatory accounts cast in terms of causes that are universal by virtue of their being first in some order of causes), and that the latter kind of account is the ultimate aim of scientific inquiry. Thus, in the de Anima, after having given a general account of the soul according to which it is 'the first actuality of a natural body which has organs, ${ }^{, 33}$ and having then distinguished the various powers of soul, Aristotle states:

It is clear, then, that it is in the same way as with figure that there will be one definition of soul; for in the former case there is no figure over and above the triangle and the others which follow it in order, nor in 
the latter case is there soul over and above those mentioned [sc., the nutritive, the sensitive, etc.]. Even in the case of figures there could be produced a common definition which will fit all of them but which will not be peculiar to any one. Similarly too with the kinds of soul mentioned. For this reason it is foolish to seek in both these cases and in others for a common definition which will be a definition peculiar to no actually existing thing and will not correspond to the proper indivisible species, to the neglect of one which will. (de An II 3, 414b20-8, trans. Hamlyn)

Although one might think that Aristotle here speaks of identifying the kind of soul peculiar to a lowest species, in fact he proceeds to give accounts of the various powers of soul, one of which - i.e., the nutritive power of the soul - is described, as we have seen, both as the 'first' and as the 'most common' power of soul. In other words, in the wake of this passage, Aristotle actually gives accounts of those causes which are more or less universal according to their position in the order of the powers of the soul. He then leaves it to the reader to formulate (say) an account of that kind of soul which is peculiar to plants. ${ }^{34}$

This passage at least serves as an indication that for Aristotle the ultimate aim of scientific inquiry is the formulation of causal accounts which are cast in terms of causes that are universal with respect to some domain by virtue of being first in some order of causes. But that Aristotle also conceives of the other kind of causal account as a means towards the formulation of such accounts as these is implied by what he

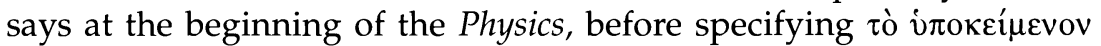
and $\tau \dot{\alpha} v \alpha \nu \tau i ́ \alpha$ (i.e., substrate and contraries) as intrinsic principles of both composite substances and certain accidental compounds. Having opened the Physics by noting that when an object of inquiry has 'principles, causes, or elements, it is through an acquaintance with these that knowledge and understanding is attained,' and having then concluded that 'in the science of nature ... our first task will be to try to determine what relates to principles, ${ }^{35}$ Aristotle states:

34 Admittedly, the class of plants is not a lowest species. But the general point still holds: we have a descent from causes that are universal in relation to some domain because they are themselves universals to more particular causes that are universal with respect to the very same domain, though not because they are themselves universals, but because they occupy a certain position in some order of causes.

35 Ph I 1, 184a10-16, trans. in Barnes (1984). Note that this passage likewise serves as 
The natural way of doing this is to start from the things which are more knowable and clear to us and proceed towards those which are clearer and more knowable by nature; for the same things are not knowable relatively to us and knowable without qualification. So we must follow this method and advance from what is more obscure by nature, but clearer to us, towards what is more clear and more knowable by nature. Now what is to us plain and clear at first is rather confused masses, the elements and principles of which become known to us later by analysis. Thus we must advance from universals to particulars; for it is a whole that is more knowable to sense-perception, and a universal is a kind of whole, comprehending many things within it, like parts. ( $P h$ I 1, 184a16-26, trans. in Barnes [1984])

Given that the aim in natural philosophy is to identify the first principles and causes of natural things, in this passage Aristotle would seem to be characterizing the progression from the kind of causal account formulated in terms of causes that are themselves universals, to the kind of causal account formulated in terms of causes that are first in some order, as a progression from what is 'clearer and more knowable to us' ('̇א

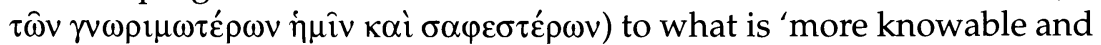

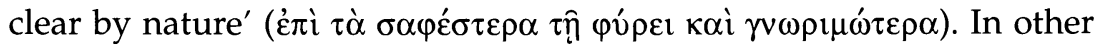
words, causal accounts of the former kind are conceived by Aristotle to be means towards the formulation of causal accounts of the latter kind.

Now, it is important to note that the thesis of this paper is not that theology is simply to be identified with that division of metaphysics which deals with the principles and causes of substance. The thesis is that theology forms one part of this division. As we shall see, metaphysics deals also with a cause that is universal by virtue of the fact that it is itself a universal - i.e., 'the actual'.

One last remark must be made before proceeding to a discussion of some of Aristotle's physical works. Note that according to this conception of the distinction between two senses in which a cause can be universal, it is in principle possible that one and the same cause should be universal in both senses. For an intermediate genus may be first relative to certain genera that are coordinate with it, and also a universal un-

an indication that for Aristotle the ultimate aim of scientific inquiry is the formulation of explanatory accounts cast in terms of causes that are universal by virtue of being first in some order of causes. 
der which more particular causes are subsumed, these more particular causes being such as to constitute an order according to which one of them is universal because first.

\section{The Complementarity of Aristotle's Theoretical Works}

Since, according to Aristotle, every science is a science of some genus, and scientific understanding of a genus involves an understanding of its causes, ${ }^{36}$ when looking at (say) the de Caelo, it is important to ask oneself whether its discussion of the elements, insofar as they are possessed of natural local motions, is a discussion of the subject of the science presented in the de Caelo, or rather a discussion of certain causes and principles of this work's subject-genus. My claim here is that reflection on Aristotle's de Caelo leads to the conclusion that this work is devoted to natural or composite substances as such, and that when dealing with the heavenly bodies and the natural local motions of the elements in the de Caelo Aristotle understands himself to be dealing with the principles and causes of natural substances as such. ${ }^{37}$

More generally, once it is recognized, the notion of a cause that is universal with respect to some domain by virtue of being first in some order of causes can be seen to serve as a principle of organization in the discussions to be found in the three treatises that follow the Physics in the standard ordering of Aristotle's works - i.e., the de Caelo, the de Generatione et Corruptione and the Meteorologica. Specifically, discussions occur in these three treatises in an order that reflects the topic of discussion's position in an order of causes: the earlier the topic of discussion's position in some order of causes, the earlier does discussion of it take place (i.e., in an earlier chapter, book or work). Thus, for any lowest species of perishable substance $x$, both the de Caelo and the de Generatione et Corruptione are properly understood as dealing with $x^{\prime}$ s causes (causes more or less remote). But the de Caelo, which was meant by Aristotle to

36 Alternatively: 'involves an understanding of the causes of the genus' members precisely insofar as they are members of that genus.'

37 Thomas Aquinas likewise claims that the de Caelo is devoted to the genus of natural substances. He also anticipates me in holding that the de Generatione et Corruptione is devoted to the genus of perishable substances. See the prooemia to his commentaries on the de Caelo and the de Generatione et Corruptione. 
be read before the other two treatises, ${ }^{38}$ deals with causes of $x$ which are more remote in some order of causes than are those causes of $x$ which are dealt with in the de Generatione et Corruptione and the Meteorologica. At the same time, since, as we have seen, the domain or genus with respect to which a cause serves as a cause is more extensive the more remote the position of that cause is in some order of causes, the de Caelo stands to the de Generatione et Corruptione (for example) as the study of a higher genus stands to the study of a lower genus.

\section{The de Caelo}

According to Aristotle, every composite substance admits of motion with respect to place and so has a local motion that is natural to it. ${ }^{39}$ It is not true, however, that for Aristotle all the local motions natural to a composite substance attach to the substance precisely insofar as it is a natural substance. For the self-motion of an animal (which must necessarily be a local motion ${ }^{40}$ ) is not something that attaches to an animal, according to Aristotle, precisely insofar as it is a natural substance, since there are many natural substances incapable of self-motion. Rather, it attaches to animals like horses and dogs precisely insofar as they are members of that genus whose members are all and only those animals which are capable of self-motion. ${ }^{41}$ For this reason, Aristotle distinguishes between two senses of 'locomotion' ( $\varphi$ o ó). In the broad sense, 'locomotion' is said of both (i) self-motions (e.g., walking, crawling, galloping) and (ii) the kinds of local motion that attach to composite substances merely insofar as they are composite substances

38 The opening section of the Meteorologica (338a20-7) clearly refers back to the topics of the de Caelo and the de Generatione et Corruptione. Moreover, as noted by both Williams $(1982,132)$ and Joachim $(1926,164)$, at GC I 8, 325b33-4, Aristotle can be seen to be referring back to discussions that occur at Cael III 1, III 7 and IV 2. I take it, then, that the order: 1. de Caelo, 2. de Generatione et Corruptione, 3. Meteorologica, is the one in which Aristotle meant the works to be read.

39 See Cael I 2, 268b14-16.

40 See $P h$ VIII 2, 253a14-15: 'we say that the animal itself originates not all of its motions but its locomotions' (trans. in Barnes [1984]). See also Ph VIII 6, 259b6-7.

41 See last note. That not all animals, according to Aristotle, are self-movers (i.e., capable of moving themselves locally) is made clear at Sens 1, 436b12-37a3, and at GA I 1, 715a26-b21. 
(e.g., motion downward). In the narrow sense, however, 'locomotion' is said only of the latter. As Aristotle explains in the Physics:

Motion in respect of place has no name either general or particular: but we may designate it by the general name of locomotion, though strictly the term locomotion is applicable to things that change their place only when they have not the power to come to a stand, and to things that do not move themselves locally. ( $P h \mathrm{~V} 2,226 \mathrm{a} 32-\mathrm{b} 1$, trans. in Barnes [1984])

In this passage Aristotle states that in the strict sense of 'locomotion' the self-motion of an animal (e.g., walking and crawling) does not count as a local motion. But elsewhere he notes that an animal, besides having local motions that attach to it in virtue of its being a self-mover, also has local motions which attach to it merely in virtue of its having a body (which is not a self-mover). As Aristotle puts it in Physics VIII 4:

[T]he animal as a whole moves itself naturally; but the body of the animal may be in motion unnaturally as well as naturally: it depends upon the kind of motion that it may chance to be suffering and the kind of element of which it is composed. (Ph VIII 4, 254b17-20, trans. in Barnes [1984])

Here Aristotle distinguishes between (i) the local motion that is natural to the entire animal (i.e., natural to the animal qua self-mover) and (ii) the local motion that is natural to the body of the animal (i.e., natural to the animal qua composite substance). The latter motion, which counts as a local motion in the strict sense (since the body of an animal is not a self-mover), is further said to depend on 'the kind of element of which' the animal 'is composed.' Informing this claim is Aristotle's view that the local motion which is natural to a substance composed of the elements (understanding 'local motion' in the strict sense) depends on which of the elements preponderates in it. As Aristotle explains in the de Caelo:

Bodies are either simple or compounded of such; and by simple bodies I mean those which possess a principle of movement in their own nature, such as fire and earth with their kinds, and whatever is akin to them. Necessarily, then, movements also will be either simple or in some sort of compound - simple in the case of the simple bodies, compound in that of the composite-and the motion [in the lat- 
ter case] is according to the prevailing element. (Cael I 2, 268b26-9a2, trans. in Barnes [1984])

Thus, in the passage from Physics VIII 4 quoted above, not only does Aristotle distinguish between two kinds of local motion that can attach to a single animal; he also notes that, since the local motion that is natural to the body of an animal, or to the animal qua composite substance, (e.g., motion downward) can differ from the local motion that is natural to the entire animal, or to the animal qua self-mover (e.g., walking, crawling, galloping), it follows that, when the animal is moved by itself, this local motion is liable to be unnatural to the body of the animal, or to the animal qua composite substance (which locomotion, being violent, involves effort). ${ }^{42}$

Assuming, then, that the local motion natural to the body of an animal can still, in some sense at least, be called a motion of the animal (as I have assumed), it is true to say that every composite substance is possessed of a local motion that is natural to it, even if we understand 'locomotion' here in the strict sense (according to which a self-motion does not count as a local motion). From this it follows that local motion, in the strict sense, pertains to all natural substances precisely insofar as they are natural substances.

Now, my claim here is that the subject-genus of the de Caelo is none other than the genus of natural (or composite) substances. This claim, it should be noted, is not new. It was also advanced by Paul Moraux in the introduction to his edition of the de Caelo, largely on the basis

42 Indeed, precisely because a self-motion is liable to be a motion that is unnatural for the body of the self-mover, and is thus liable to involve effort, Aristotle denies that the motions of the heavenly bodies are due to souls inherent in them just as an animal's self-motions are due to its soul. See Cael II 1,284a11-31: 'The ancients gave to the Gods the heaven or upper place, as being alone immortal; and our present argument testifies that it is indestructible and ungenerated. Further, it is unaffected by any mortal discomfort, and, in addition, [its motion is] effortless; for it needs no constraining necessity to keep it to its path and prevent it from moving with some other movement more natural to itself. Such a constrained movement would necessarily involve effort - the more so, the more eternal it were - and would be inconsistent with perfection. Hence we must not believe the old tale which says that the world needs some Atlas to keep it safe ... . Nor, again, is it possible that it [i.e., the motion of the heavens] should persist eternally by the necessitation of a soul. For a soul could not live in such conditions painlessly or happily, since the movement involves constraint, being imposed on the first body, whose natural motion is different, and imposed continuously.' (trans. in Barnes [1984]) 
of Aristotle's claim, right at the beginning of the work, that natural philosophy is for the most part concerned with bodies and magnitudes, as well as their attributes and motions. ${ }^{43}$ But another basis for the claim can be discerned if we keep in mind Aristotle's view that local motion, in the strict sense, is a per se attribute of natural substances (i.e., an attribute belonging to natural substances precisely insofar as they are natural substances). For if the subject of the de Caelo is indeed natural substance, one would expect to find in this work an account of the principles and causes of natural substances qua natural substances, all of which causes and principles should serve to explain this per se attribute of body. And indeed, a careful examination of the de Caelo's various discussions bears this out.

For example, in this work Aristotle discusses (i) the ether (see especially de Caelo I 2-4), which is susceptible of change only with respect to place, and (ii) the four sublunary elements (fire, air, water and earth) insofar as they are possessed of natural locomotions (see de Caelo IIIIV). And as we have seen, Aristotle takes the local motion natural to a body composed of one or more elements to be a function of the element which preponderates in it. Thus, a body composed entirely of ether (e.g., the sphere of the fixed stars) will naturally move in a circle (just as ether does), while a body composed for the most part of earth will naturally move to the centre of the cosmos (just as earth does). In other words, the elements, qua possessed of natural local motions, are explanatory of the natural tendency of mixed or non-elemental bodies to move toward certain places. In its discussion of the five elements, then, the de Caelo would seem to be concerned with the material causes of natural substances as such, since the element or elements out of which a natural substance is made serve to explain the behaviour that attaches to it precisely insofar as it is a natural substance (sc. locomotion in the strict sense identified earlier). ${ }^{44}$

Indeed, the fact that the de Caelo deals with the four sublunary elements, not in a general way, but precisely insofar as they are possessed of natural local motions, is what distinguishes its discussion of the four sublunary elements from the de Generatione et Corruptione's treatment

43 Moraux (1965, x-xi)

44 According to Aristotle, all sublunary mixed bodies are composed of all four sublunary elements (see GC II 8). Only the heavenly bodies are composed of a single element - i.e., ether. 
of these same elements. The latter work deals with elemental transformation, or with the four sublunary elements precisely insofar as they admit of being transformed into and out of each other. In this respect, as we shall see, the sublunary elements, together with prime matter, count as first material principles of that which admits of being changed with respect to quality, quantity and substance as such (i.e., they count as first material principles of perishable substances as such), since, according to Aristotle, the quantitative, qualitative and substantial changes undergone by things composed out of the four sublunary elements presuppose elemental transformation.

Here, however, it will perhaps be objected that Aristotle's discussion of the four sublunary elements in the last two books of the de Caelo is not in fact limited to a consideration of these elements precisely insofar as they are susceptible of local motion. It is true that de Caelo IV is plausibly understood in this way, since its subject is weight and lightness - which belong in the first instance to the sublunary elements - and for Aristotle things are called light or heavy on account of their aptitude to be naturally moved with respect to place in certain ways. ${ }^{45}$ But Aristotle begins Book III of the de Caelo by announcing that it is necessary to discuss the generation and corruption of the sublunary elements - i.e., the sublunary elements insofar as they are susceptible of change with respect to substance.

A close look at de Caelo III, however, reveals that its discussion of generation is at best incomplete, and more polemical than constructive. Moreover, in many ways, Book III of the de Caelo is still very much focused on the issue of local motion.

In the first chapter of de Caelo III, after announcing that a discussion of the sublunary elements must involve a discussion of their generation and corruption, ${ }^{46}$ and must also address the question of whether there even is generation and corruption of the elements, Aristotle gives a brief review of his predecessors' theories on this subject. On the one hand, there are the Eleatic philosophers Parmenides and Melissus, who denied that there is such a thing as generation and corruption at all. These Aristotle quickly dismisses, with the explanation that their views are alien to natural philosophy: having apprehended that there must be something eternal and immutable if there is to be science, Aristotle explains, the 
Eleatics were at the same time ignorant of the existence of super-sensible entities, and therefore incorrectly ascribed to natural substances the features of eternity and immutability which instead belong to separate substances. ${ }^{47}$ On the other hand, Aristotle continues, there are those who held that all bodies are generated, some being destined to perish, while others are destined never to be destroyed. Hesiod, Heraclitus and Plato are given as examples of those who adhere to this view.

Plato, who is said to have held that bodies are 'constructed out of planes and resolved into planes again, ${ }^{48}$ at this point becomes the object of special attention. Particularly important here is the fact that, of the four physical arguments offered against Plato's theory, two take the form of arguing that the Platonic view offers no explanation of weight and lightness, which are, of course, intimately connected to the phenomenon of local motion. In other words, although Aristotle is concerned to critique Plato's theory of the elements, his focus remains on the local motions natural to the elemental bodies.

Indeed, it is significant that immediately after his critique of Plato's theory of the elements in de Caelo III 1, Aristotle begins the next chapter by offering two arguments in support of the claim that each simple body must have a natural locomotion. ${ }^{49}$ He then proceeds, in the light of this, to fault Plato and the atomists Democritus and Leucippus for the failure of their theories to accommodate the natural tendency of the elements to move in certain directions. ${ }^{50}$ In the remainder of the chapter, moreover, Aristotle argues that the sublunary bodies owe their impulse upward or downward to lightness and heaviness, ${ }^{51}$ explains the role of air in the unnatural motion of projectiles and in the acceleration of heavy falling bodies, ${ }^{52}$ and appeals to previous conclusions in support of (i) the claim that there is no such thing as the absolute generation of body, and (ii) the further claim that not all things are subject to generation. ${ }^{53}$

47 Cael III 1, 298b14-24

48 Cael III 1, 298b35-9a1, trans. Guthrie.

49 The first argument is to be found at 300a21-7 and the second at 300a27-b8.

50 Cael III 2, 300b8-1a20

51 Cael III 2, 301a22-b17

52 Cael III 2, 301b17-30

53 Cael III 2, 301b31-9 
The interest in local motion persists in de Caelo III 3-5. After explaining, in the third chapter, what he means by an element, and arguing that there must be elements, in the fourth chapter Aristotle considers and rejects theories that posit the existence of infinitely many kinds of element (i.e., the theories of the atomists and Anaxagoras), and does the same in the fifth chapter for theories that only posit the existence of a single kind of element (e.g., the theories of Thales, Anaximenes and Heraclitus). Here, many of Aristotle's arguments against these two sets of theories involve no appeal to natural local motion; but one failing common to all such theories, Aristotle points out, is their failure to recognize that for every simple local motion there is a simple body or element to which this motion is natural. Those who posit infinitely many kinds of element fail to see that there are only finitely many simple locomotions, ${ }^{54}$ and those who posit only one kind of element fail to see that there is more than one simple local motion. ${ }^{55}$

Finally, after arguing in de Caelo III 6 that the sublunary elements are not eternal, and are in fact generated from each other, in the last two chapters of Book III Aristotle criticizes various theories of elemental transformation - specifically, those of Empedocles, Democritus, and Plato, in addition to one theory whose author is not identified. In these and earlier polemics, it should be noted, it is plausible to see Aristotle as following a procedure laid down in Posterior Analytics I 2. After having argued that knowledge through demonstration requires that the knower be better convinced of the principles from which the demonstration proceeds than he is of the conclusion of the demonstration, at the end of this chapter Aristotle adds that a knower must likewise be more convinced of the principles than he is of their opposites. ${ }^{56}$ In the context of the de Caelo, the principles at issue are arguably those that make up Aristotle's theory of the elements, qua explanatory of the natural local motions belonging to bodies composed out of the elements, while the 'opposites' are the competing theories of the elements espoused by his predecessors.

With respect, then, to the objection that in Book III of the de Caelo Aristotle deals with the elements qua susceptible of substantial change, rather than with the elements qua possessed of natural local motions,

54 Cael III 4, 303b4-8

55 Cael III 5, 304b11-22

56 APo I 2, 72a37-b4 
we have seen that Aristotle's discussions in this book are largely polemical (Aristotle's own theory of elemental generation receiving its presentation later, in Book II of the de Generatione et Corruptione), and still very much centered on considerations of local motion.

There are, however, two more objections that might be made to my characterization of the de Caelo as devoted to the genus of natural substances, their causes and properties. First, although Aristotle discusses the 'first body' or ether in de Caelo I 2-4, which is explanatory of the circular motions of the heavenly bodies, the remainder of de Caelo I is devoted to establishing that the world is finite (Chapters 5-7), unique (Chapters 8-9), and eternal (Chapters 10-12). And it is far from clear how this discussion of the cosmos as a whole fits with my description of the de Caelo's subject-matter. Second, in de Caelo II 1-12 Aristotle first discusses the heavenly spheres and then the stars, both the fixed stars of the outermost sphere and the wandering stars or planets of the lower spheres. And here, too, it might be difficult to see how Aristotle's discussion fits with my characterization of the de Caelo as concerned with the genus of natural substances.

An answer to the first objection can be found in the very first chapter of the de Caelo, where Aristotle explains that body is complete or perfect inasmuch as it possesses all three dimensions. In the wake of this claim, Aristotle adds that in another sense, however, bodies limited by contact with surrounding bodies are not complete; only the 'whole' which is made up of all such bodies counts as unqualifiedly complete, in virtue of both possessing all three dimensions and being unlimited by any surrounding body. ${ }^{57}$

Of course, this doubly complete body is, in Aristotle's view, nothing other than the world as a whole. Accordingly, it is perhaps possible to see a proper understanding of the world as constituting a sort of principle in the Aristotelian system, and thereby an appropriate object of discussion in a work devoted to the genus of natural substances - i.e., in a work devoted to body. In fact, during the course of his argument for the finitude, uniqueness, and eternity of the world, it becomes clear that Aristotle's doctrine of natural local motions and natural places requires that there be only one world, finite and eternal.

With respect to the second objection - namely, that it is difficult to see how Aristotle's discussion of the heavenly bodies in de Caelo II 1-12 
fits with my characterization of the work as devoted to the genus of natural substance - the answer is easy to see when it is remembered that in Aristotle's system the heavenly bodies are the first moved movers of the cosmos, and therefore first in the order of natural efficient causes. ${ }^{58}$ In other words, just as the five elements are together first in the order of things locally moved in the sense that they serve as material causes of all other natural substances (and thereby constitute material causes of natural substances as such), so also the heavenly bodies are first in the order of moved movers, and thus serve as efficient causes of natural substances as such.

It should be remembered that on Aristotle's view the heavenly bodies, which are composed of ether, admit of being locally moved but do not admit of any other kind of motion. Indeed, this is why the domain of composite substances (which includes both heavenly and sublunary bodies) is larger than the domain of perishable substances (which includes all and only sublunary bodies). It should also be remembered that local motion is, according to Aristotle, first in the order of motions

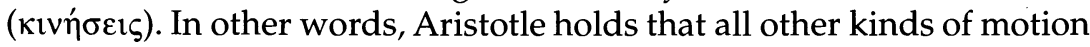
have their ultimate source or trigger in a locomotion. As he explains in the Physics:

[O]f the three kinds of motion that there are - motion in respect of magnitude, motion in respect of affection, and motion in respect of place - it is this last, which we call locomotion, that must be primary. For it is impossible that there should be increase without the previous occurrence of alteration: for that which is increased, although in a sense it is increased by what is like itself, is in a sense increased by what is unlike itself: thus it is said that contrary is nourishment to contrary: but one thing gets attached to another by becoming like it. There must be alteration, then, in that there is this change from contrary to contrary. But the fact that a thing is altered requires that there should be something that alters it, something [e.g.] that makes the potentially

58 See Metaph XII 7, 1072a21-b10. The first moved movers are not, however, first causes in the entire order of efficient causes; instead, the unmoved movers are first causes in this order. However, since the unmoved movers are not natural beings, they are not studied in physics, but instead fall under the scope of metaphysics. Moreover, since the unmoved movers are causes of the motions of the first moved movers, the unmoved movers are prior in the order of explanation to the first moved movers, for which reason metaphysics is said by Aristotle to be prior to the study of natural things at Metaph VI 1, 1026a23-33. 
hot actually hot: so it is plain that the mover does not maintain a uniform relation to it but is at one time nearer to, and at another farther from, that which is altered; and we cannot have this without locomotion. (Ph VIII 7, 260a26-b5, trans. in Barnes [1984])

Aristotle argues here that locomotion, generally taken, is first among motions because all other motions presuppose it. He first establishes that growth presupposes alteration, by drawing on his view ${ }^{59}$ that growth requires the alteration of nourishment - this alteration being, presumably, a necessary step in the nourishment's substantial change, during which it goes from (say) being banana stuff to being the proximate matter of that which is to grow (e.g., blood, in the case of blooded animals ${ }^{60}$ ). Next, Aristotle argues that alteration presupposes locomotion, since the causality of that which alters something else is only actuated when agent and patient come to be appropriately situated in space relative to each other. Accordingly, since growth presupposes alteration and alteration presupposes locomotion, it follows that locomotion is prior to both growth and alteration.

It should also be noted that, inasmuch as locomotion has species (e.g., upward and circular), it is also a universal cause because it is itself a universal. That is, locomotion is a universal cause both because it is first in the order of motions, and because it is itself a universal under which more particular kinds of locomotion are subsumed. ${ }^{61}$ For just as there is, according to Aristotle, a lowest species of matter which is first in the order of sublunary material causes (i.e., prime matter), so also there is, according to him, a lowest species of locomotion that is first in the order of locomotions - namely circular locomotion. ${ }^{62}$ Accordingly, those things which are naturally moved in a circle - i.e., the ethereal bodies of the heavens - are together first in the order of things locally moved. Moreover, since locomotion, generally, is first in the entire or-

59 Explained more fully at de An II 4, 416a19ff. and in GC I 5.

60 'The nature of the blood is the cause of many features of animals with respect to both character and perception, as is reasonable, since blood is the matter of the entire body; for nourishment is matter and blood is the last stage of nourishment' (PA II 4, 651a12-15, trans. Lennox).

61 See the last paragraph of Section II above.

62 '[M]otion in space is the first of the kinds of change, and motion in a circle the first kind of spatial motion; and this the first mover produces' (Metaph XII 7, 1072b8-10, trans. in Barnes [1984]). See also Ph VIII 9. 
der of motions, the heavenly bodies, being first in the order of things locally moved, are likewise first in the entire order of moved movers (whatever the category with respect to which there is motion), which is why Aristotle takes the heavenly ethereal spheres to be the first moved movers of the cosmos.

Also informing Aristotle's claim that the ethereal heavenly bodies are prior in the order of locally moved movers to the sublunary elements and their natural local motions is his view that everything that is moved is moved by something else. ${ }^{63}$ In the particular case of a sublunary element and its natural local motion, moreover, Aristotle holds that the moving per se cause of such a motion is none other than the efficient cause of the sublunary element's generation out of another such element. ${ }^{64}$ Taken together with Aristotle's view that the heavenly bodies, and especially the sun, are responsible for the eternal cycle of sublunary elemental change, ${ }^{65}$ this implies that the heavenly bodies are efficient causes of the sublunary elements' natural local motions.

Here, it is also worth noting that the fact that Aristotle takes the natural locomotion of the ethereal bodies to be prior to the natural locomotions of the four sublunary elements serves to explain why discussion of the ether and the heavenly bodies occurs in the de Caelo before the discussion of the four sublunary elements and their natural locomotions. As we have seen, the former discussion is to be found in the first two books of the de Caelo, while the latter is to be found in the third and fourth books of that work. Moreover, that Aristotle should take up his discussions in an order that reflects the respective positions of their objects in the various orders of causes seems to be a result of his conviction that scientific understanding of a thing involves an understanding of its principles and causes. In much the same way, as we shall see, someone who reads Aristotle's physical treatises according to their intended ordering will come to the Meteorologica's discussion of the major phenomena of the inorganic environment in which living things exist and come to be having already learned that such phenomena have their

$63 P h$ VIII 4 . It should be noted that, according to Aristotle, even in the case of selfmovers, what is per se moved (i.e., the body of the animal) is moved by something else (i.e., the soul of the animal, which, as an unmoved mover, is moved only per accidens, insofar as it belongs to the body that is moved).

64 Ph VIII 4 and Cael VI 3. See Mansion (1945, 235-7).

65 GC II 10 
efficient cause in the movements of the heavenly bodies, which have been dealt with in an earlier work.

On the whole, then, it seems that the de Caelo is fairly characterized as being concerned with natural substances as such, and their causes, particularly when we pay attention to its sustained focus on local motion, which is a per se attribute of natural substances.

\section{The de Generatione et Corruptione}

Whereas the de Caelo deals, I claim, with the genus of natural substances, the de Generatione et Corruptione deals with perishable substances as such - i.e., with the causes and principles that attach to perishable substances precisely insofar as they are perishable substances. That this is indeed the case seems to be clearly implied by what Aristotle says at the very beginning of the de Generatione et Corruptione:

Our task now is to pick out the causes and definitions of generation and corruption common to all those things which come to be and perish in the course of nature; and secondly to investigate growth and alteration, asking what each of them is, and whether we are to suppose that the nature of alteration and generation is the same or different, as they are certainly distinguished in name. (GC I 1, 314a1-6, trans. Williams $^{66}$

Note that Aristotle begins the de Generatione and Corruptione here by explicitly stating that his concern is with the causes of generation and corruption in general - i.e., with the causes of generation and corruption insofar as these two kinds of changes (to quote the Revised Oxford Translation of this passage) 'apply uniformly to all the things that come-to-be and pass-away by nature.' In other words, Aristotle is concerned, not with the kind of generation and corruption that characterizes this or that species of perishable substance, but with generation and corruption in general, the capacities for these two kinds of change being per se attributes of perishable substance, or attributes that attach to perishable substances precisely insofar as they are perishable sub- 
stances. ${ }^{67}$ Accordingly, the causes of generation and corruption, so conceived, will be causes that are (i) common to all perishable substances and (ii) explanatory of their substantial changes.

Also noteworthy here is that Aristotle proposes in this opening passage to discuss alteration, growth and diminution in the de Generatione et Corruptione as well. And this is what one should expect, granted the view that the de Generatione et Corruptione is concerned with perishable substances as such, since the capacity for substantial change, the capacity for qualitative change, and the capacity for quantitative change are all per se attributes of perishable substances. ${ }^{68}$

Now, Book I of the de Generatione et Corruptione seems to be the place to look for Aristotle's promised definitions of generation and corruption, alteration and growth. For in the first three chapters of the de Generatione et Corruptione Aristotle considers (among other things): (i) the question of whether his predecessors possessed the explanatory resources to account for generation, on the one hand, and alteration, on the other; (ii) the related question of whether they had the explanatory resources to distinguish between these two kinds of change; (iii) the question of whether generation and corruption should be understood in terms of the aggregation and segregation of indivisible bodies, as the atomists would have us believe; and (iv) the question of how one ought to distinguish between alteration and generation. Moreover, in Chapters 4 and 5, Aristotle gives general accounts of alteration and growth.

In the remaining chapters of Book I, Aristotle discusses contact ( $\dot{\eta}$ $\left.\dot{\alpha} \varphi \eta \eta^{\prime}\right)$ in Chapter 6, acting and being affected ( in Chapters 7 through 9, and mixing ( $\mu$ ' $\xi_{1 \zeta}$ ) in Chapter 10 . He does so because he recognizes that generation, although not an aggregation of indivisible bodies (as the atomists would have it), frequently does involve another kind of aggregation - i.e., mixing - and the notions

67 For this reason, I think, it is a mistake to expect-on the basis of what Aristotle says at the beginning of GC-a discussion of generation and corruption as it applies to particular species of perishable substance, as though the GC's discussion of elemental transformation were intended to be the first of many discussions, each focused on the generation and corruption of a particular species of thing. Cf. Burnyeat (2004). On my view, Aristotle discusses elemental transformation in GC II 1-8 because elemental transformations underlie those changes with respect to substance, quality and quantity which are undergone by substances composed of the sublunary elements.

68 Note that in GC Aristotle characterizes even inanimate sublunary substances as capable of growth. See, for example, GC I 5, 321b35-2a16. 
of contact, acting, and being affected are all involved in the notion of mixing.

The first book of the de Generatione et Corruptione, then, is devoted to discussions of generation and corruption, alteration and growth in general, and to an analysis of mixing, a process common to many forms of generation. De Generatione et Corruptione II 1-8, on the other hand, is devoted to a discussion of the four sublunary elements - in particular, to a discussion of prime matter, the primary contrarieties (i.e., hot/cold, dry/wet), and the mutual transformations of the elements. And in this respect, I argue, the work is to be understood as dealing with the material principles of perishable substances as such. For the sublunary elements, qua capable of mutual transformation, are first in the order of perishable substances in the sense that they serve as the matter of all other perishable substances, and are therefore causes with respect to all other perishable substances. As we have seen, in much the same way, the elements, qua possessed of natural local motions, are first in the order of natural substances in the sense that all other natural substances are composed of these five elements and possess the natural local motions they possess in virtue of the natural local motion of the element that predominates in them. With respect to the sublunary elements, qua capable of mutual transformation, on the other hand, these elements are taken to serve as principles of perishable substances as such because Aristotle holds that their changes into and out of each other underlie, or constitute a necessary condition for, the qualitative, quantitative and substantial changes of every other kind of sublunary body.

That Aristotle takes the alteration of a body composed out of the four elements to depend ultimately on elemental transformations is made clear in the following passage, in which he criticizes Empedocles (among others) for holding the view that the elements do not change into and out of each other:

[J]ust as, whilst the substance stays the same, we see change in it in respect of size - what is called growing and getting smaller - so we also see alteration; but nevertheless, it is a consequence of what is said by those who posit a plurality of principles that alteration is impossible. For the affections in respect of which we say that this takes place are differentiae of the elements; examples are hot and cold, white and black, dry and wet, soft and hard, etc. ... . If, therefore, it is impossible for water to come into being from fire or earth from water, it will be equally impossible for anything to come to be black from white, or hard from soft, and the same reasoning will apply to all the other 
properties; but precisely this is what constitutes alteration. (GC I 1, 314b13-26, trans. Williams)

Aristotle's argument here, it should be noted, seems clearly to presuppose his doctrine that each of the four sublunary elements is essentially characterized by two different qualities - one from each of the two pairs of contraries hot/cold and dry/wet - and his further view that these four qualities are primary in the sense that all other sensible qualities are somehow derived from them, or otherwise presuppose them. A consequence of this, Aristotle seems to be arguing here, is that every change of quality undergone by a mixed body presupposes a change in the ratio of its elemental constituents (some of the fire in the mixed body, for example, turning into air). ${ }^{69}$

According to Aristotle, then, elemental transformation somehow underlies the changes in quality that are undergone by bodies composed out of the four elements. But given Aristotle's view, mentioned earlier, that growth presupposes the alteration of that which accedes to the growing thing, it is clear that elemental transformation should, according to him, likewise underlie, or constitute a condition on, the changes in quantity that are undergone by bodies composed out of the four elements. In fact, Aristotle explicitly states this conclusion in de Generatione et Corruptione II $6 .^{70}$ Moreover, if generation likewise presupposes alteration, according to Aristotle, it will also turn out that elemental transformations underlie, or constitute a condition on, changes with respect of substance. But that generation, according to Aristotle, likewise presupposes alteration is strongly suggested by the following passage from the Physics:

Moreover, it would seem absurd actually to speak in this way, to speak, that is to say, of a man or house or anything else that has come

See GC II 2. That elemental transformation is a necessary condition for alteration in such bodies as are composed out of the four sublunary elements is a view repeated by Aristotle elsewhere in the GC: see, e.g., II 1, 329a24-b3, and II 4, 331a7-12.

70 In GC II 6, after criticizing Empedocles' view that the elements do not change into each other on the grounds that this would entail that the elements do not admit of being compared, Aristotle adds: 'Moreover, there would be no such thing as growth according to Empedocles, except by way of addition. Fire will grow by means of fire, 'earth will make its own body grow and ether, ether', but these are additions. Things which grow do not, in our view, grow in this way' (333a35-b3, trans. Williams). 
into existence as having been altered. Though it may be true that every such becoming is necessarily the result of something's being altered, the result, e.g., of the matter's being condensed or rarefied or heated or cooled, nevertheless, it is not the things that are coming into existence that are altered, and their becoming is not an alteration. (Ph VII 3, 246a4-9, trans. in Barnes [1984]) ${ }^{71}$

The elements, then, qua susceptible of being changed into and out of each other, are, according to Aristotle, first in the order of perishable bodies, all of which admit of change with respect to substance, quantity and quality. In other words, since elemental transformations somehow underlie all changes of quality, quantity and substance undergone by things composed out of the four sublunary elements, the latter bodies, qua susceptible of being changed into and out of each other, count as material principles of all other perishable bodies as such. ${ }^{72}$

The sublunary elements, qua susceptible of mutual transformation, are not the only principles and causes attaching to perishable substances to be considered by Aristotle in the de Generatione et Corruptione. For in Chapter 10, after having made some remarks in Chapter 9 on the need to recognize the efficient cause of generation and corruption, in addition to their material, final and formal causes, Aristotle identifies the sun as the primary efficient cause of generation and corruption in the sublunary world: the sun's daily rotation around the earth is cited as the cause of the un-ending cycle of generation and corruption in the region below the moon, while the shifting of its path in the sky between the solstices (which gives us the seasons) is cited as the cause of alternating periods of generation and corruption in various parts of the sublunary world.

71 That elemental change is required for the generation and corruption of things composed out of the four sublunary elements is also implied by the following passage: "Let it be conceded that "principles" and "elements" are good names for the primary things whose change, whether by aggregation and segregation or another change, entails that there is generation and corruption' (GC II 1, 329a5-8, trans. Williams).

72 It will perhaps be objected that on my account the sublunary elements, qua possessed of natural local motions, should be prior to these same elements, qua susceptible of mutual transformation, but that in fact the generation of a sublunary element precedes its natural local motion in time. It is perhaps with this point in mind that at Cael IV 3, 310b33-1a1, Aristotle argues that the natural local motion of a sublunary element is prior in the order of being to its generation. 


\section{The Meteorologica}

The Meteorologica deals with the genus of mixed perishable substances - i.e., non-elemental sublunary bodies - and it does so by means of an examination of the various homoeomeries to be found in the sublunary world, all of which are conceived by Aristotle to be first in the order of mixed perishable substances and therefore causes of all the other nonelemental sublunary bodies.

The first three books of the Meteorologica - or, to be more precise, the first two books together with the bulk of Book III-deal with the major phenomena to be found in the regions of fire, air and water that encircle the earth, these regions constituting part of the inorganic environment in which living things exist. ${ }^{73}$ (It should be noted that Aristotle regards the fire, air and water that fill these regions to be mixed bodies, for he takes the four sublunary elements not to exist anywhere in a pure and unmixed state - what we commonly call air, e.g., being really a mixture of all four elements in which 'elemental air' predominates. ${ }^{74}$ ) In the closing lines of Book III, $^{75}$ Aristotle gives a brief and very general account of how mixed homoeomerous bodies are generated in the earth, and then proposes to discuss such bodies and their generation next in more detail. Whether Book IV is to be understood as containing this discussion is a point of contention between commentators. ${ }^{76}$ Whatever

73 This discussion of the inorganic environment begins with Book I and ends at Book III, Chapter 6, 378a14.

74 'Neither fire nor air nor any of those we have mentioned is in fact simple, but mixed. The simple bodies are like these, but not the same as them: that which is like fire is fiery, not fire; that which is like air is aeriform; and so on in the other cases' (GC II 3, 330b21-5, trans. Williams). 'The upper region as far as the moon we affirm to consist of a body distinct both from air and fire, but varying in degree of purity and in kind [some parts, in other words, being more fiery than other parts], especially towards its limits on the side of the air [where it is more aeriform]' (Mete I 3, 340b6-10, trans. in Barnes [1984]).

75 Mete III 6, 378a15-b6

76 Most scholars now agree that Book IV was indeed written by Aristotle, though there is less agreement about two related issues: (i) did Aristotle conceive it as part of the Meteorologica? and (ii) is Book IV the detailed discussion, promised at the end of Mete III, of homoeomeries generated in the earth? On these issues, see Düring (1944, 17-22), Lee (1962, xiii-xxi), Louis (1982, x-xviii), Furley (1983) and Lewis (1996, 3-15). In opposition to Düring, I think that Mete IV does indeed belong to the Meteorologica, though I am undecided as to whether it should be taken 
the case, Book IV focuses (i) on heat and cold as efficient causes of the generation of mixed homoeomeries in general, and (ii) on the passive powers or forms that these same efficient causes give rise to in their patients.

Now, in its concern to discuss the regions of fire, air and water, $\mathrm{Me}$ teorologica I-III can be interpreted as a study of the efficient causes of the being and becoming of living things. ${ }^{77}$ And in its concern to discuss the formation of mixed homoeomerous bodies generally under the influence of heat and cold, Meteorologica IV can be interpreted as a study preliminary to Aristotle's works on living things. In both respects, the position of the Meteorologica in the standard ordering of Aristotle's treatises reflects the fact that composite homoeomeries are explanatorily posterior to the simple homoeomeries out of which they are made (simple or elemental homoeomeries being a concern of the de Caelo and the de Generatione et Corruptione). Furthermore, just as Aristotle's discussion of the first moved movers (i.e., the heavenly bodies) comes early in the intended ordering of the physical treatises, and its position in this order can be explained by appeal to Aristotle's conception of the place the first moved movers occupy in the order of natural efficient causes, so also the Meteorologica's position relative to the Aristotelian works devoted to living things (a consideration of the material parts of living things being a topic to which the very end of the Meteorologica refers as something to be discussed next) is justifiable by appeal to the fact that the movements of the inorganic environment in which living things exist are conceived to be efficient causes of their being and becoming.

With respect to the claim that the Meteorologica's discussions of the regions of fire, air and water are motivated by a concern to describe certain efficient causes of living things, it is important to bear in mind

as the discussion promised at the end of Mete III. (Lewis and Louis think that it should, while Furley thinks that it should not.)

77 Consider the following passage from Metaph II 2: 'Evidently there is a first principle, and the causes of things are neither an infinite series nor infinitely various in kind. For, on the one hand, one thing cannot proceed from another, as from matter, ad infinitum, e.g., flesh from earth, earth from air, air from fire, and so on without stopping; nor on the other hand can the efficient causes form an endless series, man for instance being acted on by air, air by the sun, the sun by Strife, and so on without limit' (994a1-8, trans. in Barnes [1984]). Note that in this passage Aristotle has in mind causes that are universal by virtue of being first in some order of causes. 
that for Aristotle the existence of a living thing involves living, and that living consists, according to him, in an assortment of activities (some of which are subordinate to others) that together have their ultimate causes in the animal's environment. As Aristotle explains in the Physics:

[W] observe that there is always some part of the animal's organism in motion, and the cause of the motion of this part is not the animal itself, but, it may be, its environment. Moreover, we say that the animal itself originates not all of its motions but its locomotions. So it may well be the case - or rather perhaps it must be the case - that many motions are produced in the body by its environment, and some of these set in motion the intellect or the appetite, and this again then sets the whole animal in motion. (Ph VIII 2, 253a11-18, trans. in Barnes [1984])

Here, Aristotle first suggests that those motions in an animal which are not self-motions have their origin in the animal's environment. He then suggests that an animal's self-motions will also in some sense have their ultimate source in the environment, though, given his claim that the soul is an unmoved mover, he would presumably want to say that there is also a sense in which some animals are the source of their own motions. Admittedly, Aristotle's tone in this passage is rather tentative. But in the following passage the claim is articulated more decisively:

We must grasp the fact ... that animals move themselves only with one kind of motion [sc. locomotion], and that this is not strictly originated by them. The cause of it is not derived from the animal itself: there are other natural motions in animals, which they do not experience through their own instrumentality, e.g., increase, decrease and respiration: these are experienced by every animal while it is at rest and not in motion in respect of the motion set up by its own agency: here the motion is caused by the environment and by many things that enter into the animal: thus in some cases the cause is nourishment - when it is being digested animals sleep, and when it is being distributed they awake and move themselves, the first principle of this motion being thus originally derived from outside. (Ph VIII 6, 259b614, trans. in Barnes [1984])

In these two passages, then, Aristotle indicates that even the self-motions of an animal (which must be locomotions) will have their ultimate origin in other motions occurring outside the animal in its environment 
(although this relation between the animal's self-motions and the motions outside the animal will be mediated by motions occurring in the parts of the animal). For even if these motions are in a sense caused by the animal itself, nonetheless, the animal's causality with respect to its self-motions is still triggered by external influences, which would therefore seem to count as necessary conditions for the exercise of an animal's causality with respect to its self-motions. The details on how to reconcile this with the familiar Aristotelian claim that the souls of some living mortal beings are unmoved movers is an issue we need not enter into here. ${ }^{78}$

In order to make clearer the sense in which the inorganic materials of the environment, qua efficient causes, are explanatorily prior to animals and living things generally, let us take, by way of example, the act of generation - which may not be vital to the life of the individual animal, but is vital for the continuation of the species. As we have seen, according to Aristotle, animals are self-movers only with respect to some of their locomotions - specifically, those attributable to the animal as a whole, or to the animal qua self-mover, e.g., walking or crawling, which are to be contrasted with such locomotions as attach to the animal only insofar as it is made of a certain kind of matter, e.g., motion downward. But there is much more to reproduction than such self-caused locomotions. There are motions in the animal that are prior to the locomotions involved in the act of mating (e.g., in the case of sanguineous vivipara, the concoction of blood into sperm in the male and the concoction of blood into menstrual fluid in the female). And, on the basis of what Aristotle says in the passage just quoted, it would seem that, according to him, the self-caused locomotions of an animal during copulation are in some way brought about by these prior motions, which are in turn brought about by the animal's environment. ${ }^{79}$ For

78 As regards the issue of reconciliation, we might suppose that for Aristotle, to claim that such-and-such a motion is self-caused, and so was originated in the soul, is insufficient as an explanation because it fails to explain why the animal should have moved itself when it did, rather than at some other time. (Consider the fact that animals often mate, for example, only in a particular season of the year-and the fact that self-motion is clearly involved in the act of mating.)

79 See GA I 4, 717b7-11, where Aristotle observes that the testes of male birds become swollen during mating season, but become nearly imperceptible once the season is over. See also GA II 4, 738a9-b4, where Aristotle states that women's menstrual periods are typically a result of the cooling effect brought about by the waning of the moon: specifically, the consequent chilling of the air is said to lower a woman's 
what else can explain why the animal actually copulates when it does? Although there is, according to Aristotle, a regress back in the realm of efficient causes from conspecific generator to conspecific generator, nevertheless, this will not explain why a generator actually generates, though the fact that a human is doing the generating will explain why it generates in the way it does, and, moreover, why the process of generation it initiates will terminate in a human being. In other words, a generator's conspecific generator may be a cause of the generator's being human, and thus in some sense a cause of the fact that, when the generator does actually generate, it will generate such a kind of thing in this or that way. But none of this gives us the cause of the generator's actually generating. Aristotle thinks that what explains or causes the generator's actually generating in very many cases is the environment and the environment's natural motions (hence the existence of specific mating seasons for most animals). ${ }^{80}$

The inorganic environmental phenomena dealt with by Aristotle in the first three books of the Meteorologica are all conceived to be the result of moist and dry exhalations ( $\alpha v \alpha \theta v \mu ı \alpha \sigma \varepsilon ı \varsigma)$ released by the earth and sea when they are heated by the sun. They include various forms of precipitation like rain, snow and hail; droughts; the various winds, their seasons and their effects on the weather; the apparent radiation of heat and light from the heavenly bodies; the formation of clouds in the lower atmosphere; the milky way, comets and shooting-stars (all three of which are taken by Aristotle to be atmospheric phenomena); the

body temperature, temporarily causing an inability to concoct blood to the degree required for nourishment (since concoction involves heat), which in turn causes the blood to accumulate in small blood vessels terminating in the vicinity of the uterus, until eventually a hemorrhage occurs.

80 HA V 8-13 contains many observations on various animals' mating seasons and on the environmental conditions that obtain during these seasons. Scattered comments regarding mating seasons and sexual habits can also be found throughout the remainder of $H A \mathrm{~V}$, and in $H A$ VI. Furthermore, Book I, Chaps. 1-30, of the Problemata contains an abundance of observations about the effects of weather on human health. Of course, some of Aristotle's conclusions about environmental influences on animals are liable to seem quaint at best. For example, at GA IV 2, 766b33-6, Aristotle explains that copulation when a north wind is blowing is more likely to result in male offspring (more likely, that is, than when copulation occurs during a south wind). And at GAV 5, 785a24-30, Aristotle explains that wind can delay the process of going grey, and that this is why hair covered with a hat goes grey more quickly. 
formation of dew and hoar-frost; earthquakes (which are said to be due to wind that has been trapped inside the earth); thunder and lightning; rainbows and haloes; the production of atmospheric phenomena like the northern lights; and many others. In each case Aristotle is concerned to identify the causes of the phenomenon. The apparent radiation of heat from the sun, for example, is said to be caused by the ignition of the combustible dry exhalation (which is warm and dry) in the upper atmosphere, which is occasioned by the sun's motion above it. ${ }^{81}$ Clouds are formed from the moist exhalation, as a consequence of the sun's heat, while rains are the result of this vapour's reverting to a watery state when the sun withdraws, whether at night or in winter (which explains, Aristotle says, why rain is more common at night or in winter ${ }^{82}$ ). Important to note here is that all the phenomena dealt with by Aristotle in the first three books of the Meteorologica can be understood either as environmental influences on the behaviours and life-cycles of plants and animals, or as indicators of such influences. For example, the frequent occurrence of comets is said to be an indicator of dry weather (which of course has an influence on living things), since the appearance of comets, like the hot and fiery appearance of the sun, is the result of combustion in the fiery substance (i.e., the dry exhalation) of the upper atmosphere. Accordingly, when there are many comets, this indicates that there is an abundance of this dry and warm exhalation which serves as their fuel. ${ }^{83}$

Also discussed by Aristotle in the first three books of the Meteorologica are rivers, springs and seas, all of which have some life-giving and life-sustaining function. Of particular interest is Aristotle's conclusion that coast-lines gradually change over time, due in large part to the silting up of rivers, which phenomenon has an effect on soil quality and thereby also an influence on the rise and decline of entire cultures and civilizations. 'In the time of the Trojan wars,' Aristotle explains,

81 Mete I 3, 341a12-36. Aristotle has recourse to such an account, at least in part, because he takes the heavenly bodies not to be made of fire, but of ether.

82 Mete II 4, 359b34-60a4

83 Mete I 7, 344b19-5a5. The appearance of haloes around the sun is likewise taken to be a sign - specifically, a sign of rain-though the fading and dissipation of haloes are taken to be signs of fine weather and wind, respectively. See Mete III 3. 
the Argive land was marshy and could only support a small population, whereas the land of Mycenae was in good condition (and for this reason Mycenae was the superior). But now the opposite is the case, for the reasons we have mentioned: the land of Mycenae has become completely dry and barren, while the Argive land that was formerly barren owing to the water has now become fruitful. (Mete I 14, 352a914, trans. in Barnes [1984])

Aristotle immediately proceeds to observe that the 'same process that has taken place in this small distriçt must be supposed to be going on over whole countries and on a large scale.'

As mentioned, the closing lines of Meteorologica III initiate a discussion of subterranean phenomena that seems meant to parallel the preceding discussions of the fiery, airy and watery regions. Whether Meteorologica IV is the place to look for the bulk of this discussion is something I leave for others to decide. Whatever the case, it seems likely that this book was at least meant by Aristotle to close the entire work, since it offers something of a bridge to his works on living things, and the beginning of the Meteorologica mentions living things as the topic to be discussed next after the business of the Meteorologica is brought to an end. ${ }^{84}$ Now, Meteorologica IV offers what is sometimes called Aristotle's chemistry. Here, Aristotle begins by explaining that, of the four primary qualities, two are active (heat and cold) and two are passive (wetness and dryness), bodies characterized especially by the latter, passive qualities being the subjects acted upon by bodies characterized principally by the former, active qualities. Aristotle then proposes to discuss 'the operations of the active qualities and the forms taken by the passive. ${ }^{85}$ The mentioned operations are discussed in Chapters 1 through 3. After explaining, in Chapter 1, that the hot and the cold are responsible for generation and decay, decay being due to the loss of intrinsic heat in the decaying thing, in Chapters 2 and 3 Aristotle distinguishes the processes by which the cold and the hot operate. The general term Aristotle uses to refer to these processes is 'concoction' $(\pi \dot{\varepsilon} \psi 1 \varsigma)$. The first such process, 'ripening' ( $\pi \dot{\varepsilon} \pi \alpha v \sigma 1 \zeta)$, is concoction by intrinsic heat (i.e., intrinsic to the thing being concocted); the second, 'boiling' ("̈ $\psi \eta \sigma ı)$ ), is concoction by means of a moist foreign heat; and 
the third, 'broiling' (ö $\pi \tau \eta \sigma 1 \varsigma)$, is concoction by means of a dry foreign heat. The forms taken on by bodies characterized especially by wetness and dryness, on the other hand, are discussed in Chapters 4 through 9. To be noted is that all the forms discussed by Aristotle here are passive powers, e.g., things like the aptitude to be softened or hardened, the aptitude to be solidified or liquefied, malleability, the aptitude to be bent or straightened, impressibility, plasticity, tractility, squeezability and combustibility. Active powers are mentioned, but not discussed, apparently on the grounds that it is on the basis of their passive potentialities that homoeomerous substances are differentiated. ${ }^{86}$ Finally, after classifying, in Chapters 10 and 11, mixed homoeomeries into different genera according as earth, water, air or fire predominates in them, in Chapter 12 (the final chapter of the Meteorologica) Aristotle announces that it is now time to discuss each homoeomery individually by reference to its form and function, though he grants that the forms and functions of homoeomerous bodies are difficult to discern in comparison with the forms and functions of the anhomoeomerous parts of living things, like hands and feet. (This difference between homoeomerous and anhomoeomerous things, he explains, is due to the fact that the former are close to pure matter, and the latter closer to pure form.) Worth noting here is that, although Aristotle speaks of discussing homoeomeries individually by reference to their form and function, to judge from his examples, his actual intention seems to be to focus on the homoeomerous parts of living things, and this as a first step in his investigation of plants and animals. Indeed, Meteorologica IV 12 reads like an introduction to his works on living things.

If, then, the final book of the Meteorologica presents the discussion promised at the end of Book III, it nevertheless devotes itself to more than just the homoeomerous bodies generated within the earth. For $\mathrm{Me}$ teorologica IV also discusses the homoeomerous parts of living things (many of which seem clearly not to be generated within the earth), at least with respect to their matter (their form and function being topics deferred to the works on animals). Indeed, it is probably no coincidence that in the final book of the Meteorologica Aristotle discusses living things' homoeomerous parts only to the extent that they can be understood in terms suitable to the explanation of inorganic homoeomeries, the discussion of what distinguishes them from inorganic 
homoeomerous bodies being left to his works on living things. Accordingly, as I claimed earlier, insofar as it concentrates on non-elemental homoeomeries, conceived of as material causes of anhomoeomerous things (whether organically united or merely conjoined in some other way), the Meteorologica can be understood as a work on mixed perishable substances generally.

\section{The Physics}

The contents of the Meteorologica, then, support a characterization of this work as focused on mixed sublunary homoeomeries, many of which constitute the inanimate environment in which living things come to be and exist, while some of them serve as material causes of living things. As such, the genus with which the Meteorologica deals is the genus of mixed sublunary substances.

The foregoing analysis, then, supports the conclusion that the order in which the de Caelo, the de Generatione et Corruptione and the Meteorologica were meant to be read has its rationale in the position which the causes that each of them discusses occupy in some order of causes: Since locomotion is first in the order of motions, and since the five simple bodies, qua possessed of simple natural locomotions, are material principles of that which is locally moved precisely insofar as it is locally moved (i.e., material principles of composite substances as such), the first work to follow the Physics in the intended order of reading is the de Caelo, which treats of these same material principles and their natural locomotions. Moreover, since the heavenly bodies are first in the order of those efficient causes which are studied in natural philosophy, ${ }^{87}$ they too are dealt with in the de Caelo. And since circular local

87 Note that Aristotle begins his proof for the existence of an eternal unmoved mover in $P h$ VIII 6 with the following prefatory remark: 'Now the question whether each of the things that are unmoved but impart motion is eternal is irrelevant to our

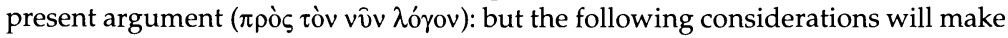
it clear that there must necessarily be some such thing, which, while it has the capacity of moving something else, is itself unmoved and exempt from all change, both unqualified and accidental' (258b12-16, trans. in Barnes [1984]). An earlier observation, at $P h$ I 9, 192a34-b1, makes it clear that Aristotle offers this prefatory remark because he holds that the discussion of the eternal unmoved movers falls to metaphysics: 'The accurate determination of the first principle in respect of form, whether it is one or many and what it is or what they are, is the province of first philosophy; so these questions may stand over till then' (trans. in Barnes [1984]). 
motion is thought to be prior to the other forms of simple local motion, in the de Caelo Aristotle deals first with the ether - whose natural local motion is circular - and the heavenly bodies, passing next to a consideration of the four sublunary elements and their natural local motions (in the third and fourth books of the de Caelo). Having dealt with the first principles of that which is locally moved, qua locally moved (i.e., the first principles of composite substances as such), Aristotle proceeds in the de Generatione et Corruptione to deal with prime matter and the four sublunary elements conceived as first material principles of that which admits of being changed with respect to quality, quantity and substance (i.e., conceived as first material principles of perishable substances as such). In the de Generatione et Corruptione, moreover, Aristotle also explains how elemental transformation depends on the changing spatial relations that obtain between the heavenly bodies (especially the sun) and various parts of the earth. Finally, in the Meteorologica, Aristotle for the first time takes up the topic of composite bodies (as opposed to simple bodies or elements), and thus discusses the composite homoeomeries, which constitute the inorganic environment in which living things exist and come to be, in addition to serving (some of them, at least) as material causes of other mixed perishable substances. In the order of efficient causes, the mixed homoeomeries that constitute the environment in which living things exist and come to be occupy a position intermediate between the heavenly bodies and perishable animate substances.

By contrast, in the first two books of the Physics, Aristotle deals with causes that are universal by virtue of the fact that they are themselves universals. As we have seen, Aristotle opens that work by remarking on the need to begin by considering such causes and principles, proceeding then to a consideration of causes that are universal by virtue of their position in some order of causes. And indeed, in Books I and II of the Physics we first find Aristotle concerned to formulate general accounts that apply to the intrinsic principles of all compounds; then we find him discussing nature generally conceived as a kind of principle of motion and rest; and finally, we find him offering accounts of the four basic kinds of cause.

Books III and IV of the Physics, moreover, deal with certain other universal principles: (i) motion in general, since a capacity is understood, according to Aristotle, in terms of its actual exercise, and the possession of a nature - i.e., the possession of a kind of internal capacity for motion and rest - is a definitive characteristic of natural substances; (ii) the infinite, since motion belongs to continuous magnitudes and 'the 
infinite presents itself first in the continuous ${ }^{88}$; (iii) place, (iv) void, and (v) time, since these are commonly thought to be necessary conditions of motion. ${ }^{89}$

Books V through VIII of the Physics, on the other hand, are largely devoted to the topic of motion, both motion in general and the question of how different kinds of motion are essentially ordered with respect to each other. ${ }^{90}$ For example, in Book V, Aristotle (i) distinguishes three senses in which a thing might be said to change (i.e., accidentally, per se, and in virtue of the change of something that belongs to it), (ii) distinguishes the three species of change (generation, corruption, and motion), (iii) defines an assortment of terms (e.g., 'contact', 'succession', and 'apart') with a view to giving an account of continuity, (iv) identifies the various senses in which a motion can be said to be 'one,' and finally, (v) examines the issue of what should count as the contrary of a given motion. Next, in Book VI, Aristotle argues that continuous things must all be infinitely divisible, and that the infinite divisibility of extension, the infinite divisibility of motion, and the infinite divisibility of time each imply the other two. This done, Aristotle then proceeds to draw out the consequences of these conclusions for our understanding of motion. Finally, in Books VII and VIII Aristotle endeavours to show that change is eternal in the universe, and that this presupposes the existence of a body which is unceasingly moved in a circle, in addition to an eternal unmoved mover. I have already had occasion to observe that in the course of their development Books VII and VIII of the Physics articulate many points of doctrine necessary for a proper understanding of the large-scale structure of the entire argument that follows the Physics and extends up to the de Anima, i.e., the large-scale structure of the argument that spans the de Caelo, the de Generatione et Corruptione

$88 P h$ III 1, 200b17-18, trans. in Barnes (1984). Aristotle, however, will conclude that the infinite exists only potentially, since, he argues, it is impossible for an infinite magnitude to exist, and body admits of being infinitely divided only in the sense that one can always carry on dividing, but not in the sense that it will ever actually be divided into infinitely many parts.

89 Aristotle's discussion of the void, however, is largely polemical in character, undertaken only in recognition of the fact that a void is widely held, at least in some quarters, to be necessary for motion. Aristotle himself holds that a void is impossible and that it is not, in fact, a necessary condition of motion.

90 Aristotle himself was accustomed to referring to the latter half of the Physics as his work on motion. See Ross (1936, 1-19). 
and the Meteorologica. For example, in this book we find part of the rationale underlying the claim that the ether is prior to the four sublunary elements in the order of locally moved movers.

\section{Conclusion}

It would seem, then, that in the treatises following the Physics in the intended ordering of his works, Aristotle takes up, for the first time, the issue of causes that are universal by virtue of their position in some order of causes. Again, the order in which the de Caelo, the de Generatione et Corruptione and the Meteorologica were meant to be read can be seen to have its rationale in the position which the causes that each of them discusses occupy in some order of causes. As mentioned earlier, when Aristotle takes up the discussions of causes that are universal because first, and does so in such a way that a cause which is universal with respect to some domain is discussed before a cause that is universal with respect to some more restricted sub-domain, this can be seen to reflect Aristotle's own conviction that scientific understanding of an object involves an understanding of its causes. Thus, when he comes to discuss something that is a universal cause with respect to some domain, its causes (which are universal causes with respect to a larger, more inclusive domain) will have already been identified and discussed in an earlier chapter, book or work. The only exception to this rule is due to the fact that the very first movers of the cosmos, the eternal unmoved movers, fall to be studied by another science, distinct from physics i.e., metaphysics - since physics deals with natural substances, and the unmoved movers are not natural substances. In other words, just as the heavenly bodies are first in the order of composite substances, the eternal unmoved movers are first in the order of substances generally, and therefore causes with respect to substances, and indeed beings, generally. But the cases are not entirely analogous: since the heavenly bodies, taken together, have causes which are distinct from themselves, while the eternal separate substances do not, ${ }^{91}$ the eternal unmoved movers are first principles without qualification (since, given that the unmoved movers do not have principles distinct from themselves, they serve as

91 See APo II 8, 93a3-9 for a passage in which Aristotle recognizes that some kinds of thing have no principle distinct from themselves. Clearly, Aristotle takes the unmoved movers to be things of this kind. 
principles of their own being), whereas the heavenly bodies are first principles only in a qualified way - i.e., they are first principles, specifically, in the natural realm.

Considered in this light, the theological focus of first philosophy, insofar as first philosophy deals with the causes and principles of that which is qua thing that is, makes perfect sense. Just as the de Caelo, say, deals with composite substances generally, but focuses its attention on those natural substances which serve as principles and causes of composite substances as such, so also the Metaphysics deals with being in general, but focuses much of its attention on those beings which serve as principles and causes of being qua being (i.e., the unmoved movers, the objects of theology). Moreover, many of the nagging doubts about the universality of theology are resolved by keeping the foregoing discussion in mind: the notion that the study of some particular kind of being is in some sense universal because that kind of being is first in some order of causes can be seen to be at work in the physical treatises of Aristotle. Furthermore, the foregoing discussion puts us in a position to answer a question that might arise from what Aristotle says in the passage from Metaphysics VI 1 quoted at the beginning of this paper. This passage, again, ran as follows:

One might indeed raise the question whether first philosophy is universal, or deals with one genus, i.e., some one kind of being; for not even the mathematical sciences are all alike in this respect - geometry and astronomy deal with a certain particular kind of thing, while universal mathematics applies alike to all. We answer that if there is no substance other than those which are formed by nature, natural science will be the first science; but if there is an immovable substance, the science of this must be prior and must be first philosophy, and universal in this way, because it is first. And it will belong to this to consider being qua being - both what it is and the attributes which belong to it qua being. (Metaph VI 1, 1026a23-33, trans. in Barnes [1984])

Given the conclusion that the heavenly ethereal bodies are not absolutely first principles, since there is something prior to the entire order of moved movers, it is easy to see the rationale informing the last two sentences of this passage: Aristotle's point is simply that if the order of moved movers (together with their properties) were coextensive with the order of all being, then there would be no science prior to physics, since there would be nothing distinct from, or explanatorily prior to, the things that exist according to nature. But since the entire order of 
being is larger than the order of naturally existing things, and there are things explanatorily prior to the entire order of naturally existing things (i.e., the eternal separate substances), there is a science that deals with these prior things. And further, since these prior things are first in the order of explanation generally, or principles both of themselves and of every other being, they will be principles of beings precisely insofar as they are beings (or, simply put, principles of being). Accordingly, since scientific understanding of an object requires an understanding of its causes, both proximate and remote, the science that studies these first things will be universal in the sense that an understanding of them will be involved in the understanding of any being - either because that being is one of the first beings or because it is causally dependent on them.

Finally, consider again Aristotle's characterization of metaphysics as the science of being qua being. So conceived, metaphysics involves a determination of the causes and principles of beings insofar as they are beings, and in this regard it is to be contrasted with the various special sciences, which deal with the principles and causes of things insofar as these things figure in some particular genus of thing that is. Now the intelligent student who takes up Aristotle's Metaphysics, upon reading this characterization of the science in question, will wonder what Aristotle means by claiming that, where $x$ is related to $y$ as a genus is related to one of its species, something, qua $x$, has such and such causes, while the very same thing, qua $y$, has such and such 'other' causes. In particular, the reader will want to know whether Aristotle should be taken as holding that an individual thing has different principles or causes, one of which attaches to it insofar as it has the status of a being, another insofar as it has the status of a perishable substance, and yet another insofar as it has the status of an animal, etc. Or is it rather the case that, in speaking of the causes and principles of something qua $x$, Aristotle has in mind suitably general conceptions of a thing's individual principles and causes (e.g., 'mover'), the generality of these conceptions being such as to make them expressive of the individual causes that attach to any $x$ (e.g., any composite substance)?

As the foregoing discussion makes plain, the answer to this question is that, according to Aristotle, the search for the causes of $x$ qua $y$ is in part a search after suitably general conceptions of a thing's individual causes and principles (e.g., 'matter for generation'), and in part a search after more particularly conceived (though still universal) causes (e.g., prime matter). In other words, the distinction between causes that are universal because they are themselves universal, and causes that are 
universal by virtue of their position in some order of causes, just is the distinction between suitably general conceptions of a thing's individual causes and more particularly conceived causes. This, I claim, explains why one part of metaphysics deals with a cause or principle that is universal with respect to the order of being because it is itself a universal - i.e., the actual - while another part deals with a cause or principle that is universal with respect to the same domain, but universal because first - i.e., the divine, which is first in the order of being because it is first in the order of the actual (since the essence of the divine consists in pure actuality). ${ }^{92}$ Moreover, when Aristotle deals first with the actual in Metaphysics IX, and then proceeds to deal with the beings that are first in the order of the actual in Metaphysics XII, this can be understood as another instance of his proceeding from causes that are universal with respect to some domain by virtue of the fact that they are themselves universal, to causes that are universal with respect to the same domain because of their position in some order of causes - i.e., an instance of

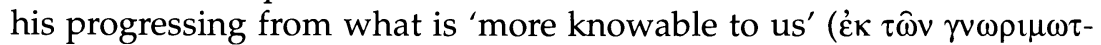

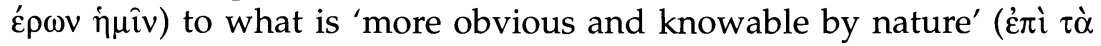

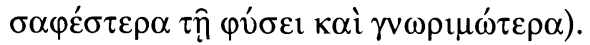

To conclude this paper: Considered in the light of the foregoing discussion of the de Caelo, the de Generatione et Corruptione and the Meteorologica, their respective subject matters and how these are related, the theological focus of the Metaphysics can be seen to be consistent with Aristotle's usual practice in his physical works. In his physical works, discussions occur in an order that reflects the topic of discussion's position in an order of causes: the earlier the position of the cause under discussion, and hence the greater the domain with respect to which it serves as a cause, the earlier does discussion of it take place. Informing this manner of proceeding is Aristotle's view that scientific understanding of anything requires an understanding of its causes. Accordingly, in the Metaphysics Aristotle takes theology to be in some sense universal

92 For Aristotle, the potential, as such, exists only by virtue of there being something actual that can bring the potential to actuality. So, we can say that, within the realm of being, the actual is the cause of the potential. But there is something that is first in the realm of the actual: the unmoved movers. Hence, although we can say that the actual as such is a cause of the potential, we can more specifically say that a particular kind of actually existing thing, i.e., the genus of unmoved movers, is likewise a cause of the potential as such in the realm of being, since the unmoved movers are causes of the actual as such, and the actual as such is the cause of the potential as such. 
because he holds that an understanding of the unmoved movers is involved in the scientific understanding of any being (given that scientific understanding of an object requires an understanding of all its causes) - either because that being is an unmoved mover, or because it is causally dependent on the unmoved movers. ${ }^{93}$

Department of Philosophy 438 General Classroom Building University of Missouri-Columbia

Columbia, MO 65201 U.S.A. duartes@missouri.edu

93 I would like to extend my heartfelt thanks to James F. Ross and Susan Sauvé Meyer for the many hours they spent in discussions with me about the issues raised in this paper. I would also like to thank Charles Kahn, Jack Kultgen and Jon McGinnis for their feedback on various drafts of this paper. 


\section{References}

Aquinas, Thomas. 1964. In Duodecim Libros Metaphysicorum Aristotelis Expositio, eds. M.-R. Cathala and Raymundi M. Spiazzi (Turin \& Rome: Marietti).

Aubenque, Pierre. 1962. Le problème de l'être chez Aristote: Essai sur la problématique aristotelicienne (Paris: Presses Universitaires de France).

Barnes, Jonathan, ed. 1984. The Complete Works of Aristotle: The Revised Oxford Translation (Princeton, NJ: Princeton University Press).

Barnes, Jonathan. 1993. Aristotle: Posterior Analytics, 2nd edn. (Oxford: Clarendon Press).

Berti, Enrico. 2001. 'Multiplicity and Unity of Being in Aristotle', Proceedings of the Aristotelian Society 101: 185-207.

Bostock, David. 1994. Aristotle: Metaphysics Z and H (Oxford: Clarendon Press).

Burnyeat, Myles. 2004. 'Introduction: Aristotle on the Foundations of Sublunary Physics', in Frans de Haas and Jaap Mansfeld, eds., Aristotle: On Generation and Corruption, Book I, Symposium Aristotelicum (Oxford: Clarendon Press) 7-24.

Charlton, William. 1970. Aristotle: Physics I and II (Oxford: Clarendon Press).

Décarie, Vianney. 1961. L'objet de la métaphysique selon Aristote (Paris and Montréal: Vrin and L'Institut d'Études Médiévales).

Düring, Ingemar. 1944. Aristotle's Chemical Treatise: Meteorologica, Book IV (Göteburg, Sweden: Elanders boktryckeri aktiebolag).

Elders, Leo. 1962. 'Aristote et l'objet de la métaphysique', La Revue Philosophique de Louvain 60: $165-83$.

Follon, Jacques. 1992. 'Le concept de philosophie première dans la «Métaphysique» d'Aristote', La Revue Philosophique de Louvain 88: 387-421.

Fraser, Kyle. 2002. 'Demonstrative Science and the Science of Being qua Being', Oxford Studies in Ancient Philosophy 22: 43-82.

Frede, Michael. 1987. 'The Unity of General and Special Metaphysics: Aristotle's Conception of Metaphysics', in Michael Frede, Essays on Ancient Philosophy (Minneapolis: University of Minneapolis Press) 81-95.

Furley, David J. 1983. 'The Mechanics of Meteorologica Iv: A Prolegomenon to Biology', in P. Moraux and J. Wiesner, eds., Zweifelhaftes im Corpus Aristotelicum: Studien zu einigen Dubia, Akten des 9. Symposium Aristotelicum (New York: Walter de Gruyter) 73-93.

Gill, Mary Louise. 1989. Aristotle on Substance: The Paradox of Unity (Princeton, NJ: Princeton University Press).

Gómez-Lobo, Alfonso. 1978. 'Aristotle's First Philosophy and the Principles of Particular Disciplines: An Interpretation of Metaph. E, 1, 1025 ${ }^{\mathrm{b}} 10-18^{\prime}$, Zeitschrift für philosophische Forschung 32: 183-94. 
Guthrie, William K. C. 1939. Aristotle: On the Heavens (Cambridge, MA: Harvard University Press).

Hahn, Robert. 1979. 'Aristotle as Ontologist or Theologian? Or, Aristotelian Form in the Context of the Conflicting Doctrines of Being in the Metaphysics', Southwest Journal of Philosophy 10: 79-88.

Hamlyn, David W. 1993. Aristotle: De Anima Books II and III (with passages from Book I) (Oxford: Clarendon Press).

Irwin, Terence. 1988. Aristotle's First Principles (Oxford: Clarendon Press).

Jaeger, Werner. 1948. Aristotle: Fundamentals of the History of his Development, 2nd edn., trans. Richard Robinson (Oxford: Oxford University Press).

Joachim, Harold. 1926. Aristotle On Coming-To-Be and Passing-Away (Oxford: Clarendon Press).

Lee, H. D. P. 1962. Aristotle: Meteorologica, 2nd edn. (Cambridge, MA: Harvard University Press).

Lennox, James G. 2001. Aristotle: On the Parts of Animals (Oxford: Clarendon Press).

Leszl, Walter. 1975. Aristotle's Conception of Ontology (Padua: Editrice Antenore).

Lewis, Eric. 1996. Alexander of Aphrodisias: On Aristotle's Meteorology 4 (Ithaca, NY: Cornell University Press).

Louis, Pierre. 1982. Aristote: Météorologiques (Paris: Les Belles Lettres).

Ludwig, Walter. 1989. 'Aristotle's Conception of the Science of Being', The New Scholasticism 4: 379-404.

Mansion, Augustin. 1945. Introduction à la physique aristotélicienne, 2nd edn. (Louvain and Paris: Institut Supérieur de Philosophie and Vrin).

Mansion, Augustin. 1956. 'L'objet de la science philosophique suprême d'après Aristote, Métaphysique, E, 1', Mélanges de philosophie grecque offerts à Mgr Diès par ses élèves, ses collègues et ses amis (Paris: Vrin) 151-68.

Merlan, Philip. 1960. From Platonism to Neoplatonism, 2nd edn. (The Hague: Martinus Nijhoff).

Merlan, Philip. 1986. 'On the Terms "Metaphysics" and "Being-qua-Being"', The Monist 52: 174-94.

Moraux, Paul. 1965. Aristote: $d u$ ciel (Paris: Belles Lettres).

Natorp, Paul. 1888. 'Thema und Disposition der aristotelische Metaphysik', Philosophische Monatshefte 24: 37-65 and 540-574.

Owens, Joseph. 1978. The Doctrine of Being in the Aristotelian Metaphysics, 3rd edn. (Toronto: The Pontifical Institute of Mediaeval Studies).

Patzig, Gunther. 1979. 'Theology and Ontology in Aristotle's Metaphysics', in J. Barnes, M. Schofield and R. Sorabji, eds., Articles on Aristotle, Vol. 3: Metaphysics (London: Duckworth) 33-49. 
Reale, Giovanni. 1979. The Concept of First Philosophy and the Unity of the Metaphysics of Aristotle, trans. by John Catan (Albany: SUNY Press).

Ross, David. 1936. Aristotle: Physics. A Revised Text with Introduction and Commentary (Oxford: Clarendon).

Verbeke, Gérard. 1979. 'La physique d'Aristote est-elle une ontologie?', Pensamiento 35: 171-93.

Williams, Christopher J. F. 1982. Aristotle: De Generatione et Corruptione (Oxford: Clarendon Press). 